\title{
Modeling of Microstructural Evolution in an MCrAIY Overlay Coating on Different Superalloy Substrates
}

\author{
M.S.A. KARUNARATNE, I. DI MARTINO, S.L. OGDEN, D.L. OATES, \\ and R.C. THOMSON
}

\begin{abstract}
A multicomponent, one-dimensional diffusion model that was developed for simulating microstructure evolution in coated gas turbine blade systems has been used to compare the phase structures of three MCrAlY coated superalloy systems. The model is based on finite differences and incorporates oxidation and equilibrium thermodynamic computations. The superalloy substrates considered were the nickel-based superalloy CMSX-4, a high-Cr singlecrystal superalloy, and a cobalt-based MAR-M509, and these were all coated with an MCrAlY bond coat of similar composition. The results predicted by the model have been compared with similar experimental systems. The model can predict many features observed experimentally and therefore can be expected to be a useful tool in lifetime prediction and microstructural assessment of turbine blade systems based on superalloys. The work also highlighted the fact that for a given coating, the phase evolution within system is dependent on the substrate material.
\end{abstract}

DOI: $10.1007 / \mathrm{s} 11661-011-0897-3$

(C) The Minerals, Metals \& Materials Society and ASM International 2011

\section{INTRODUCTION}

OPERATING temperatures within gas turbine engines are being raised continuously in search of higher efficiency exposing the turbine blades and vanes to increasingly harsher environments (e.g., References 1 and 2). As a result, there is greater demand for the components to be made more resistant to oxidation and corrosion. Designing components with improved performance requires a deeper understanding of how the microstructure of coated alloy systems evolves during service. Computer models can help in this regard by extending our understanding of the microstructural evolution processes without recourse to traditional but more expensive experiments at high temperatures. In addition, a well-tuned model can assist service engineers by providing valuable parameters, such as the remaining life of a blade system or their temperature limitations. The development of a model with these attributes was described in detail in an earlier paper, ${ }^{[3]}$ and validated against a particular experimental system. In this article,

M.S.A. KARUNARATNE, Research Associate, and R.C. THOMSON, Professor of Materials Engineering, are with the Department of Materials, Loughborough University, Loughborough LE11 3TU, United Kingdom. Contact e-mail: M.Karunaratne@lboro.ac.uk I. DI MARTINO, formerly PhD Student, with the Department of Materials, Loughborough University, is now Corporate Metallurgist/Engineer, with International Power plc, Senator House, London EC4V 4DP, United Kingdom. S.L. OGDEN, formerly PhD Student, with the Department of Materials, Loughborough University, is now Materials Engineer, with E.ON New Build and Technology, Technology Centre, Ratcliffe-on-Soar, Nottingham NG11 OEE, United Kingdom. D.L. OATES, formerly PhD Student, with the Department of Materials, Loughborough University, is now with RWE npower, Windmill Hill Business Park, Whitehill Way, Swindon, Wiltshire SN5 6PB, United Kingdom.

Manuscript submitted October 11, 2010.

Article published online October 18, 2011 the model is used in conjunction with experimental observations to demonstrate the pivotal role of the substrate in determining the microstructure evolution by considering the same MCrAlY coating composition on three different substrates. Therefore, the information contained in this article should be helpful to coating system designers for turbine blades.

\section{BACKGROUND}

It is common to manufacture industrial turbine components from either $\mathrm{Ni}-$, $\mathrm{Co}-$, or $\mathrm{Fe}$ - based superalloys and protect them additionally by an MCrAlY-based coating system $(\mathrm{M}=\mathrm{Ni}$, Co and/or Ta). Such coatings owe their protection to a dense surface layer of oxide that consists primarily of $\mathrm{Al}_{2} \mathrm{O}_{3}$. For the long-term stability of the oxide scale and, hence, the protection of the substrate, maintaining a substantial reservoir of $\mathrm{Al}$ in the coating is crucial. During service, the coating loses Al to two distinct processes: First, it is consumed by the oxide scale that undergoes many cycles of spallation and reforming. Second, it diffuses into the substrate, which normally has a lower concentration of $\mathrm{Al}$. When the $\mathrm{Al}$ concentration reaches a critical value, less protective oxides start to form, which is deleterious to coating behavior. At this stage, the coating may be stripped and reapplied.

The microstructural evolution in the coating is affected by not only the composition of the coating but also that of the substrate. Modern superalloy chemistries are optimized for high creep strength, whereas those of coatings are designed for prolonged oxidation and corrosion resistance. The chemical differential between the coating and substrate causes elements to interdiffuse across the common interface. Initially, MCrAlY coatings typically consist of a combination of the $\beta$ (NiAl), $\gamma^{\prime}$ $\left(\mathrm{Ni}_{3} \mathrm{Al}\right)$, and $\gamma(\mathrm{Ni})$ phases. The removal of $\mathrm{Al}$ from the 
coating over time reduces the phase fraction of $\beta$, which transforms to a mixture of less Al-rich $\gamma$ and $\gamma^{\prime}$. The superalloy substrate, however, primarily has a two-phase $\gamma-\mathrm{Ni} / \gamma^{\prime}$ microstructure if nickel based or primarily $\gamma$-Co if Co based. The interdiffusion zone that is created at the substrate/coating interface has a distinct microstructure unlike the coating and/or substrate and may also contain topologically close packed (TCP) phases and numerous carbides.

\section{THE COUPLED NUMERICAL MODEL}

The one-dimensional diffusion model is based on solving the Fick's equations for concentrations using a time-stepping, finite-difference calculation scheme. The predicted concentration profiles at a particular time-step are used as a basis for calculating the phase profiles across the system. The phase distribution computed at a time-step is in turn used to determine the interdiffusion coefficient matrices for the next time-step. The oxidation sub-model provides one boundary condition for the diffusion model. A comprehensive description of the model is provided elsewhere, ${ }^{[3]}$ and hence only a brief outline is provided here.

\section{A. Diffusion Model}

For a multicomponent system with $n$ elements, the diffusion of a species can be mathematically described by means of Fick-Onsager representation ${ }^{[4,5]}$

$$
\frac{\partial C_{i}}{\partial t}=\sum_{j=1}^{n-1}\left\{\tilde{D}_{i j}^{n} \frac{\partial^{2} C_{j}}{\partial x^{2}}+\left(\sum_{k=1}^{n-1} \frac{\partial}{\partial C_{k}} \tilde{D}_{i k}^{n} \frac{\partial C_{k}}{\partial x}\right) \frac{\partial C_{j}}{\partial x}\right\}
$$

where $i$ and $j$ are diffusing components. The interdiffusion coefficient matrix $\tilde{D}_{i j}^{n}$ is expressed in relation to a solvent $n$, in this case element $\mathrm{Ni}$, and $C_{j}$ is the concentration of element $j$. The variables $x$ and $t$ are the diffusion distance and time, respectively. Temperature- and concentration-dependent interdiffusion coefficients were obtained from several published sources, ${ }^{[6-19]}$ additional details of how these coefficients were modeled can be found in Reference 3 .

In the model, the differential terms in Eq. [1] were replaced by their finite-difference (F-D) equivalents as detailed in Reference 3. The explicit scheme was used to solve for concentrations of all elements except for rapidly diffusing carbon, for which the Crank and Nicolson implicit F-D method was used. ${ }^{[20]}$

\section{B. Oxidation Model}

For oxidation, the model proposed by Meier et al. ${ }^{[25]}$ for a Ni-Co-Cr-Al based bond coat was used. The model assumes that only $\mathrm{Al}$ is oxidized at the coating surface, and the diffusion of elements within the oxide is not considered in the current model. For isothermal oxidation, the boundary condition at the oxide/coating interface is given as the rate of $\mathrm{Al}$ consumption, where the thickness $\delta$ of the oxide scale in $\mu \mathrm{m}$ is given by

$$
\delta=\left[\exp \left\{Q\left(\frac{1}{T_{0}}-\frac{1}{T}\right)\right\} t\right]^{n}
$$

where $Q$ is a constant and equal to $27777.4, T$ is the temperature in Kelvin, $T_{0}$ is $2423.7 \mathrm{~K}, t$ is time in seconds, and $n$ is 0.332 .

\section{Thermodynamic Model}

The thermodynamic equilibrium calculations were performed using the Application Interface ${ }^{[22]}$ of MTDATA. ${ }^{[23]}$ The MTDATA program (National Physical laboratory, Middlesex, UK) consists of a numerical technique for the minimization of Gibbs free energy of a chemical system and was used in conjunction with a thermodynamic database for Ni-based superalloys, Ni-DATA ${ }^{[24]}$ The code calls the MTDATA application interface at each time-step, with the concentration at each node in the diffusion grid sequentially. The thermodynamic calculations in turn return a description of equilibrium phases that are likely to be present at each node. This description includes the fractional phase constitution and the composition within each of the phases. These data are used by the diffusion code to calculate an effective diffusion coefficient for each element at each node, after taking diffusion within each phase into account.

Each thermodynamic calculation is computationally expensive because of the inclusion of a large number of elements and alloy phases. Furthermore, there is a requirement to perform a large number of such calculations because of the need to solve at each spatial grid point at every time step. Therefore, to address these problems, the simulations have been performed in parallel so as to minimize the computational run time. This has been achieved by partitioning the spatial grid points between multiple processors, which is possible because the thermodynamic calculations at each spatial grid point are independent.

\section{IMPLEMENTATION}

The diffusion was modeled initially only at two separate locations where concentration gradients are steepest, as independent phenomena. These were (1) near the oxide/coating interface and (2) at the coating/ substrate interface. Considering interdiffusion at the two zones as independent problems allowed computational resources to be concentrated more efficiently in the early stages.

\section{A. Initial Concentration Distribution}

An error function solution was used to assign the coating and substrate compositions initially to the computational nodes to provide a smooth transition between the coating and substrate compositions.

The compositions of the coating and substrates used in these simulations are given in Table I. Three different substrates were examined: CMSX-4, a conventional 
Table I. Bond-Coat and Substrate Compositions Used in the Current Study

\begin{tabular}{|c|c|c|c|c|}
\hline \multirow[b]{2}{*}{ Element } & \multirow[b]{2}{*}{$\begin{array}{l}\text { Bond-Coat } \\
\text { AMDRY-997 }\end{array}$} & \multicolumn{2}{|c|}{ Composition (wt pct) } & \multirow[b]{2}{*}{ CMSX-4 } \\
\hline & & MAR-M509 & $\begin{array}{l}\text { Substrates } \\
\text { High-Cr } \\
\text { Superalloy }\end{array}$ & \\
\hline $\mathrm{Al}$ & 8.5 & 0.2 & 3.6 & 5.6 \\
\hline $\mathrm{Co}$ & 23 & 54.8 & 9 & 9.6 \\
\hline $\mathrm{Cr}$ & 15 & 23.7 & 12 & 6.4 \\
\hline Mo & 0 & 0 & 1.9 & 0.6 \\
\hline $\mathrm{Ni}$ & 46.5 & 10.5 & 60.43 & 60.9 \\
\hline $\mathrm{Ta}$ & 7 & 3.6 & 5 & 6.5 \\
\hline $\mathrm{Ti}$ & 0 & 0.2 & 4.1 & 1 \\
\hline $\mathrm{Re}$ & 0 & 0 & 0 & 3 \\
\hline $\mathrm{W}$ & 0 & 7 & 3.9 & 6.4 \\
\hline $\mathrm{C}$ & 0 & 0 & 0.07 & 0 \\
\hline $\mathrm{Y}$ & $0.3-0.7$ & 0 & 0 & 0 \\
\hline
\end{tabular}

single crystal Ni-based superalloy, a high Cr containing single crystal Ni-based superalloy, and a conventionally cast Co based superalloy. Although the element yttrium is an important reactive element in modern overlay coating compositions, the presence of $\mathrm{Y}$ was neglected in the model as it is not allowed for within the thermodynamic database and because of its small concentration in the coating. However, Y is generally thought to form oxides within such coatings and does not take part in the formation of any of the main coating phases, and therefore, the predictions of the phases within the bulk of the coating are likely to be a reasonable representation. It is at the same time recognized that Y may have a significant impact on the oxidation rate and scale adhesion, which will be addressed in future research.

\section{B. Moving Boundaries and Expansion of Zones}

The interface between the oxide scale and coating represents a moving phase boundary and as such was treated numerically according to the grid-point motion technique suggested by Murray and Landis. ${ }^{[25]}$ The grid either shrinks or expands at each time step, depending on the direction of the expansion, and also it requires redistribution of grid points at each time step.

The simulation process was based on a flexible grid scheme, and as such, the diffusion zones were allowed to expand or contract with time to match the position of the moving zones and phase boundaries. The expansion process involved relocation of the nodes and interpolating the concentrations onto the new grid locations using a spline-interpolation process.

\section{MATERIALS AND EXPERIMENTAL PROCEDURE}

The substrates for the MAR-M509 alloy were provided in the form of plates of size $40 \mathrm{~mm} \times 40 \mathrm{~mm} \times 6 \mathrm{~mm}$, whereas for the CMSX-4 and High-Cr superalloy, they were obtained in the form of cylindrical bars of $13 \mathrm{~mm}$ in diameter. The AMDRY-997 bond-coat was applied using low pressure plasma spray (LPPS) in each case, followed by a standard heat treatment for the coating. The MARM509 specimens additionally had an air plasma sprayed (APS) thermal barrier coating applied on top of the bond coat. After sectioning into smaller specimens, the samples were aged isothermally in air between $1123 \mathrm{~K}$ and $1323 \mathrm{~K}$ $\left(850{ }^{\circ} \mathrm{C}\right.$ and $1050^{\circ} \mathrm{C}$ ) for times up to 10,000 hours in laboratory furnaces. After aging, the specimens were air cooled, mounted in conducting Bakelite, and prepared using standard metallographic routines. The samples were observed using various field emission gun scanning electron microscopes (FEGSEMS) equipped with energy dispersive X-ray analysis (EDS) facilities, which were used for concentration (standardless) measurements. In the majority of experiments a Zeiss 1530 VP FEGSEM (Carl zeiss, Inc., Maple Grove, MN) was used in combination with an EDAX Pegasus combined electron back scatter diffraction (EBSD) and EDS system (EDAX Inc., Mahwah, NJ). The precise phase identification was done using a combination of selected-area electron diffraction and EDS in a transmission electron microscope (TEM), and once the chemistry of the different phases was established, the results were correlated with SEM analysis. Therefore, the contrast from the backscattered electron (BSE) images were widely used to identify bulk phases.

The total thicknesses of the MCrAlY coating measured under the microscope were approximately $250 \mu \mathrm{m}$ for the MAR-M509 and High-Cr superalloy substrate samples. In CMSX-4 substrate samples, samples, the thickness was $350 \mu \mathrm{m}$ except in the samples aged at $1223 \mathrm{~K}\left(950^{\circ} \mathrm{C}\right)$, which had a coating thickness of $215 \mu \mathrm{m}$. These values were used in simulations, such that the variation in coating thickness is accounted for in the model.

\section{A. Model validation}

The predictions made by the model were found to agree well with several key measurements obtained from the experimental specimens, and a sample of these comparisons is presented here. Figure 1 compares the variation of $\gamma^{\prime}$ with aging time in the central region of the bond coat of the MAR-M509 substrate specimen. The measured $\gamma^{\prime}$ area fraction was obtained using image analysis on BSE micrographs. The images were taken at a magnification of 3000 times, and each measurement in Figure 1 was obtained by averaging the results from 10 images. The simulated curves represent the mean $\gamma^{\prime}$ volume fraction in the central $50 \mu \mathrm{m}$ of the coating, calculated from weight fraction output using the densities of each phase. At both $1123 \mathrm{~K}$ and $1223 \mathrm{~K}\left(850{ }^{\circ} \mathrm{C}\right.$ and $\left.950{ }^{\circ} \mathrm{C}\right)$, the measured and simulated $\gamma^{\prime}$ fractions show an increase, probably as the $\beta$ phase converts to the $\gamma^{\prime}$ and $\gamma$ phases. At $1123 \mathrm{~K}$ $\left(850^{\circ} \mathrm{C}\right)$ the measured area fractions at 5000 and 10 000 hours correspond closely with model predictions. However, at $1223 \mathrm{~K}\left(950^{\circ} \mathrm{C}\right)$, the simulation curve slightly underpredicts the measured phase fraction, but such deviations could be expected as a result of the differences in area (measured) and volume (simulated) fractions.

Figure 2 compares the experimentally measured and predicted concentration profiles of $\mathrm{Al}, \mathrm{Co}$, and $\mathrm{Cr}$ across 


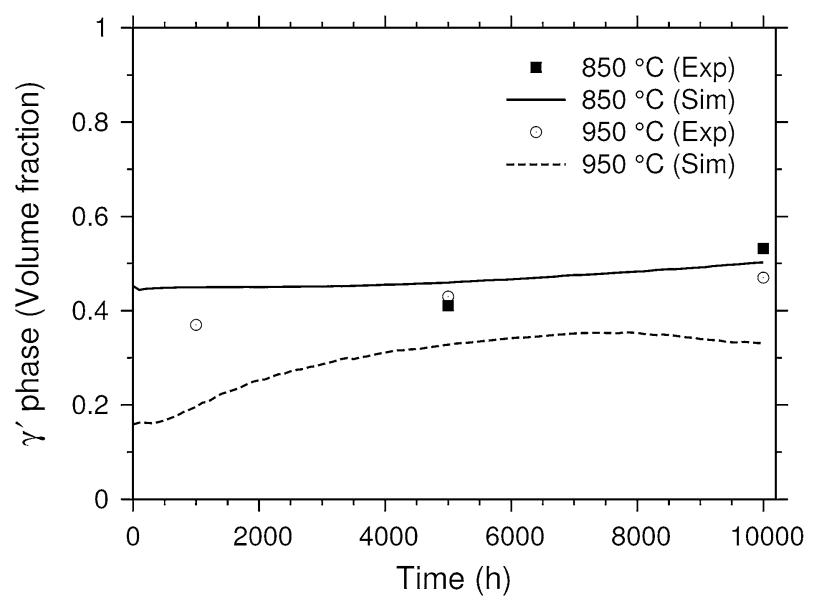

Fig. 1-Comparison of $\gamma^{\prime}$ phase fraction measured at the center of the coating against simulation predictions as a function of time in the AMDRY-997 coated MAR-M509 substrate samples after aging at $1123 \mathrm{~K}$ and $1223 \mathrm{~K}\left(850^{\circ} \mathrm{C}\right.$ and $\left.950{ }^{\circ} \mathrm{C}\right)$.

the bond-coat in CMSX-4 substrate samples after aging at $1123 \mathrm{~K}\left(850{ }^{\circ} \mathrm{C}\right)$ for 10,000 hours. The concentration profiles were obtained using energy dispersive X-ray microanalysis (EDS) attached to an SEM. The measured values show significant scatter across the coating, which is a common observation in bond-coat materials, ${ }^{[26]}$ and is believed to be caused by the electron beam of the SEM overlapping multiple phases. Despite the spread, the measured concentrations show a good agreement with those of the simulation for all three elements. The measured profile shows a slightly larger thickness for the coating, but this deviation is consistent with the variability observed in the as-deposited coating thickness for this sample.

Figure 3 illustrates how the measured thickness of the oxide scale formed on the bond-coat of the High-Cr superalloy substrate compares with the model predictions at $1123 \mathrm{~K}$ and $1223 \mathrm{~K}\left(850{ }^{\circ} \mathrm{C}\right.$ and $\left.950{ }^{\circ} \mathrm{C}\right)$. The average scale thickness plotted was calculated using measurents at several points across the scale using a FEGSEM. The graphs show that the model used in the simulation consistently underestimates the measurements at both temperatures, although the general trend is on par with the predictions. The systematic difference can be explained by the possibility of the presence of other oxides, such as chromia, in addition to the main aluminium oxide, which is assumed to be the only oxide present by the current model. There is a need to implement more complex oxidation models in the future that take into account all phenomena observed experimentally.

\section{RESULTS AND DISCUSSION}

\section{A. AMDRY-997 Coating on MAR-M509 substrate}

1. Observations after aging at $1123 \mathrm{~K}\left(850^{\circ} \mathrm{C}\right)$ for 1000 hours

Figure 4 shows an example of the concentration profiles predicted by the model for the MAR-M509 substrate samples after ageing at $1123 \mathrm{~K}\left(850^{\circ} \mathrm{C}\right)$ for

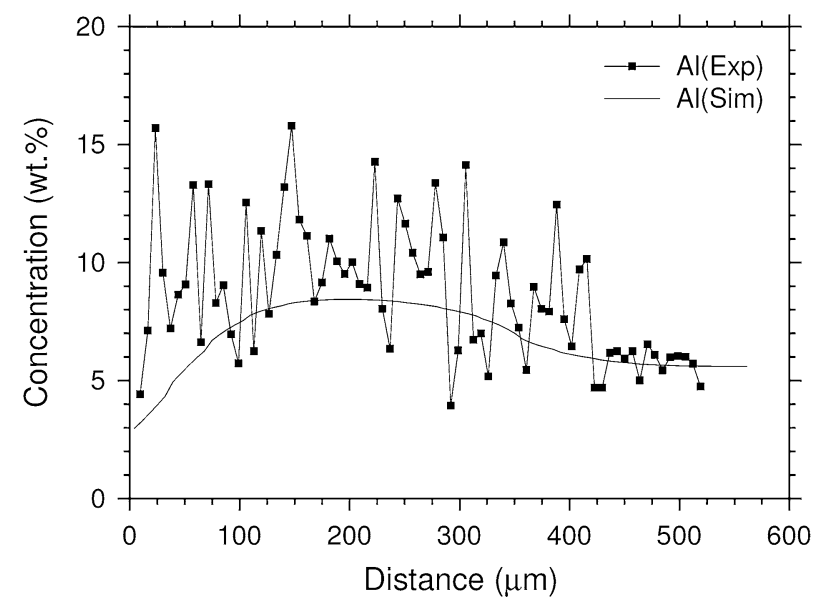

(a)

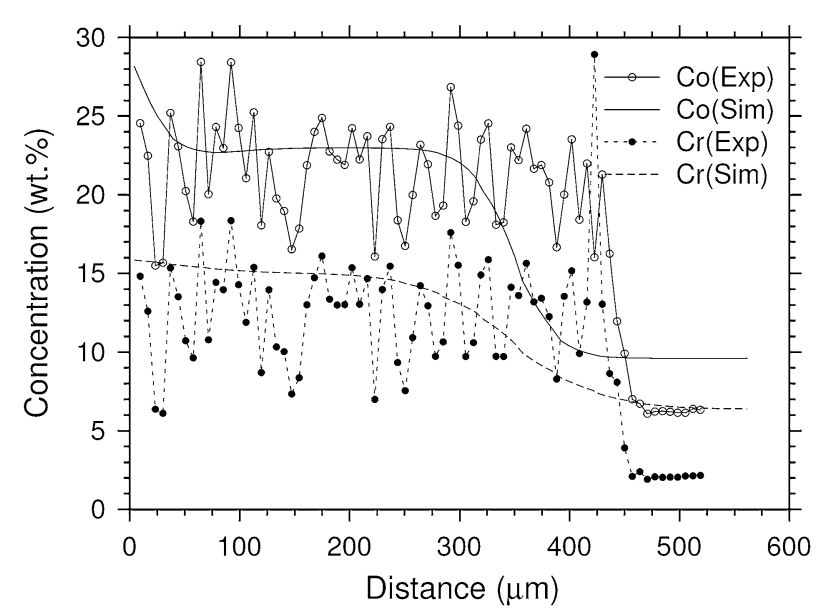

(b)

Fig. 2-Predicted concentration profiles (Sim) compared with experimental profiles (Exp) measured using EDS across the coating and interdiffusion zones of the AMDRY-997 coated CMSX-4 substrate samples, after aging at $1123 \mathrm{~K}\left(850^{\circ} \mathrm{C}\right)$ for $10000 \mathrm{~h}$ : (a) $\mathrm{Al}$, and (b) Co and $\mathrm{Cr}$.

1000 hours. One noticeable feature is that the profile for Al in Figure 4(a) shows a drop near the oxidation interface because $\mathrm{Al}$ is consumed by the scale formation process. In contrast, the elements $\mathrm{Co}, \mathrm{Cr}$, and $\mathrm{Ta}$ in the coating, which are not predicted to contribute to the scale, show a slight increase at that interface because of their build-up caused by the receding oxidation interface. All elements except $\mathrm{Ta}$, which has near-equal concentrations in the substrate and coating, show substantial interdiffusion at the coating-substrate interface.

The predicted phase profiles corresponding to the concentrations in Figure 4 are given in Figure 5. According to Figure 5(a), the coating of this system is mainly a mixture of $\gamma^{\prime}$ and approximately equal amounts of the $\beta, \sigma$, and $\gamma$ phases, whereas the MAR-M509 substrate consists primarily of $\gamma$ with a small fraction of $\gamma^{\prime}$. The coating also contains a small percentage of $\mathrm{M}_{23} \mathrm{C}_{6}$ carbides, and the substrate reveals minor amounts of $\mu$ and MC carbides, as shown in Figure 5(b). The creation of $\beta$ depleted zones near the oxidation affected zone 


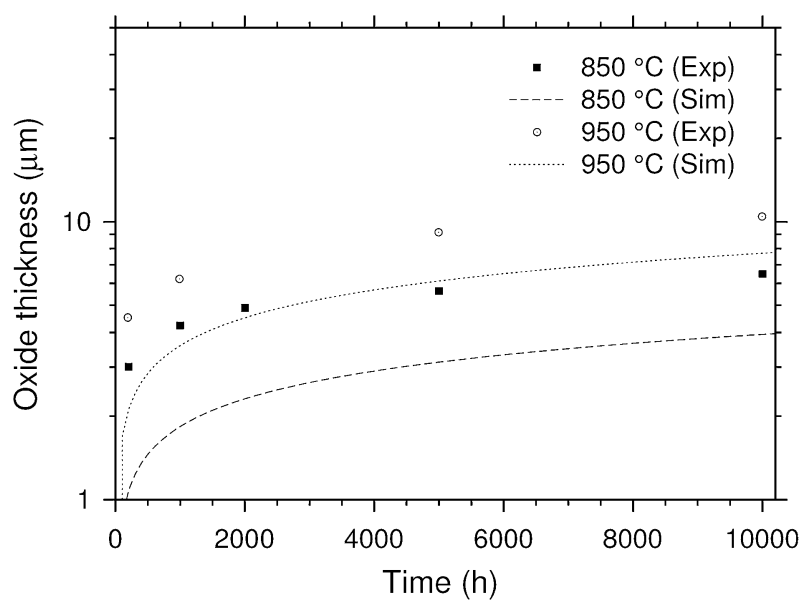

Fig. 3-Predicted and measured oxide scale thicknesses at $1123 \mathrm{~K}$ and $1223 \mathrm{~K}\left(850^{\circ} \mathrm{C}\right.$ and $\left.950^{\circ} \mathrm{C}\right)$ in the AMDRY-997 coated High$\mathrm{Cr}$ superalloy substrate samples.

(OAZ) and the coating-side of the interdiffusion zone, and the $\gamma^{\prime}$ peaks observed near the $\beta$ depleted areas are interesting features. The $\beta$ depleted zones and sharp $\gamma^{\prime}$ peak found in the OAZ in particular can be observed in many experimental samples of this system.

A micrograph of a representative area of the bulk of the coating, which underwent aging at $1123 \mathrm{~K}\left(850^{\circ} \mathrm{C}\right)$ for 1000 hours, is shown in Figure 6. The area consists primarily of an intimate mixture of $\gamma, \gamma^{\prime}, \beta$, and a phase containing a high concentration of $\mathrm{Cr}$. Although this phase was not identified conclusively, its high $\mathrm{Cr}$ content suggests a possible linkage to either the $\sigma$ phase or the $\mathrm{M}_{23} \mathrm{C}_{6}$ carbide phase, which are predicted for the region in Figure 5.

\section{Observations after aging at $1223 \mathrm{~K}\left(950^{\circ} \mathrm{C}\right)$} for 1000 hours

The graphs presented in Figure 7 give the phase predictions after aging at the temperature $1223 \mathrm{~K}$ $\left(950^{\circ} \mathrm{C}\right)$ for 1000 hours in the AMDRY-997-coated MAR-M509 system. In comparison to the results shown previously for $1123 \mathrm{~K}\left(850{ }^{\circ} \mathrm{C}\right)$ for the same aging period, the profiles are more diffused as expected because of increased temperature exposure. Most notably, in the bulk of the coating, the predicted amount of $\gamma$ phase has increased, whereas the $\gamma^{\prime}$ fraction has decreased considerably. The $\sigma$ phase predicted at $1123 \mathrm{~K}\left(850{ }^{\circ} \mathrm{C}\right)$ is completely absent at $1223 \mathrm{~K}\left(950{ }^{\circ} \mathrm{C}\right)$, but as for the lower temperature, $\mathrm{M}_{23} \mathrm{C}_{6}$ carbides are predicted to be present in the coating and $\mu$ and $\mathrm{MC}$ carbides are present in the substrate material. The interdiffusion zone is much wider compared with $1123 \mathrm{~K}\left(850^{\circ} \mathrm{C}\right)$.

These phase profiles can be compared with the corresponding micrograph in Figure 8. Even though the micrographs at both temperatures $1123 \mathrm{~K}$ and $1223 \mathrm{~K}$ $\left(850^{\circ} \mathrm{C}\right.$ and $\left.950^{\circ} \mathrm{C}\right)$ share many features, including the type of phases found at $1223 \mathrm{~K}\left(950{ }^{\circ} \mathrm{C}\right)$, the $\gamma$ phase is more abundant after 1000 hours. This observation is in line with the simulation outcome. A Cr-rich phase is again detected, and this phase corresponds to the $\mathrm{M}_{23} \mathrm{C}_{6}$ carbide phase, which is favored by the simulation.

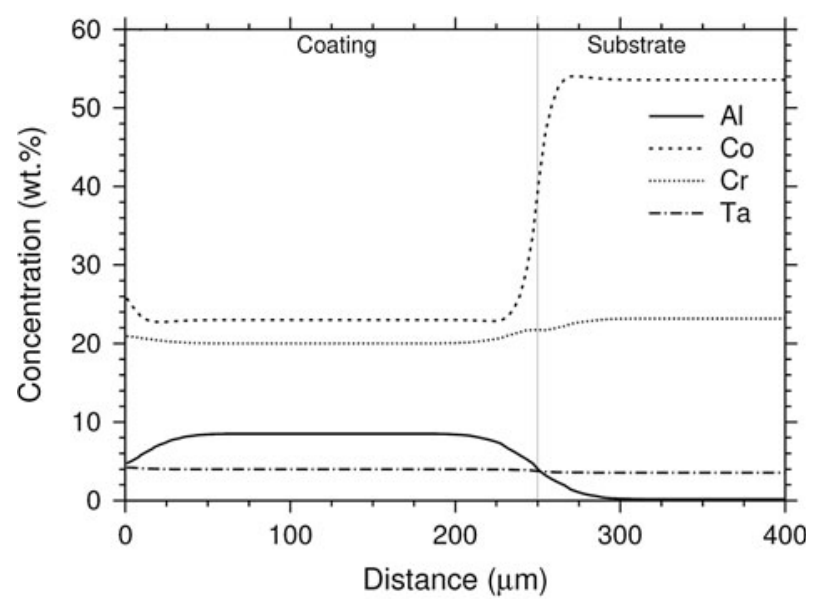

(a)

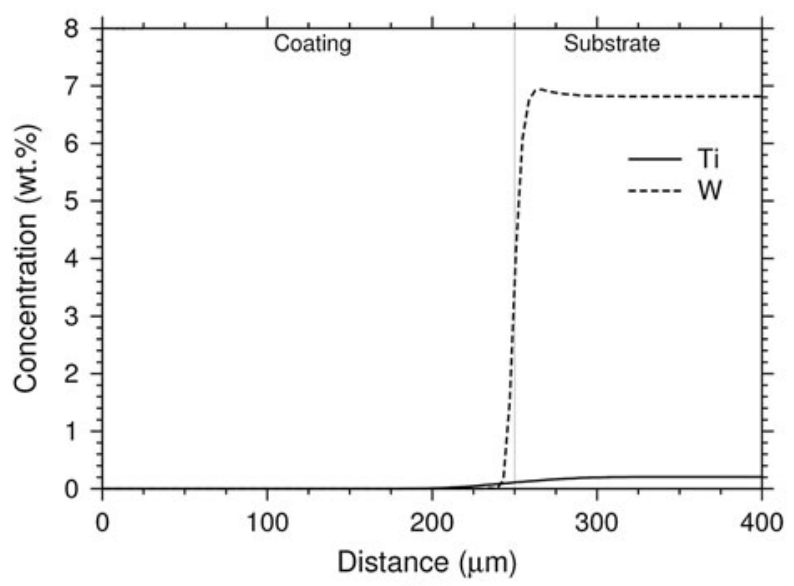

(b)

Fig. 4-Predicted concentration profiles across the coating and interdiffusion zones of the MAR-M509 substrate samples, after aging at $1123 \mathrm{~K}\left(850^{\circ} \mathrm{C}\right)$ for $1000 \mathrm{~h}$.

\section{B. AMDRY-997 Coating on a High-Cr Superalloy Substrate}

1. Observations after aging at $1123 \mathrm{~K}\left(850^{\circ} \mathrm{C}\right)$ for 200 hours

The simulated phase profiles at $1123 \mathrm{~K}\left(850^{\circ} \mathrm{C}\right)$ for 200 hours are shown in Figure 9. Because of the low temperature and the relatively short heat treatment, the profiles seem much less diffused; the bulk of the coating is a mixture of $\gamma^{\prime}, \gamma, \beta$, and $\sigma$ as expected and is similar to the AMDRY-997/MAR-M509 samples simulated at $1123 \mathrm{~K}\left(850^{\circ} \mathrm{C}\right)$ (Figure 5). A narrow, sharp $\gamma^{\prime}$ peak is observed near the oxidation interface. At the interdiffusion zone, a narrow and sharp peak ( $75 \mathrm{wt}$ pct) of $\gamma^{\prime}$ can be observed, which is associated with a sharp drop $(0 \mathrm{wt}$ pct $)$ in the $\gamma$ phase. According to simulation predictions, the substrate is prone to TCP phase formation, and in particular the $P$ phase, and the $\mathrm{M}_{23} \mathrm{C}_{6}$ carbide phase is predicted to be prevalent throughout the system. The predictions for the interdiffusion zone can be compared with experimental observations with reference to the micrographs shown in Figure 10. The narrow band of $\gamma^{\prime}$ predicted in the phase 


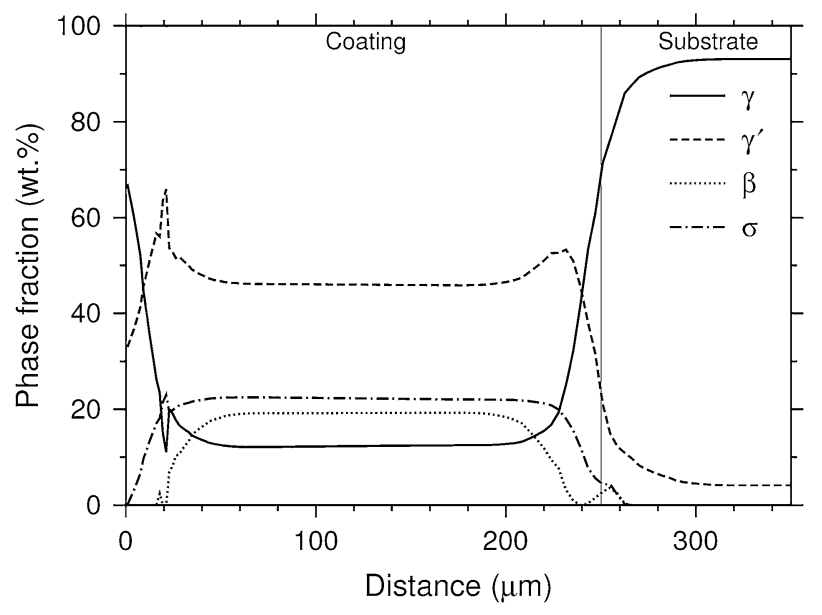

(a)

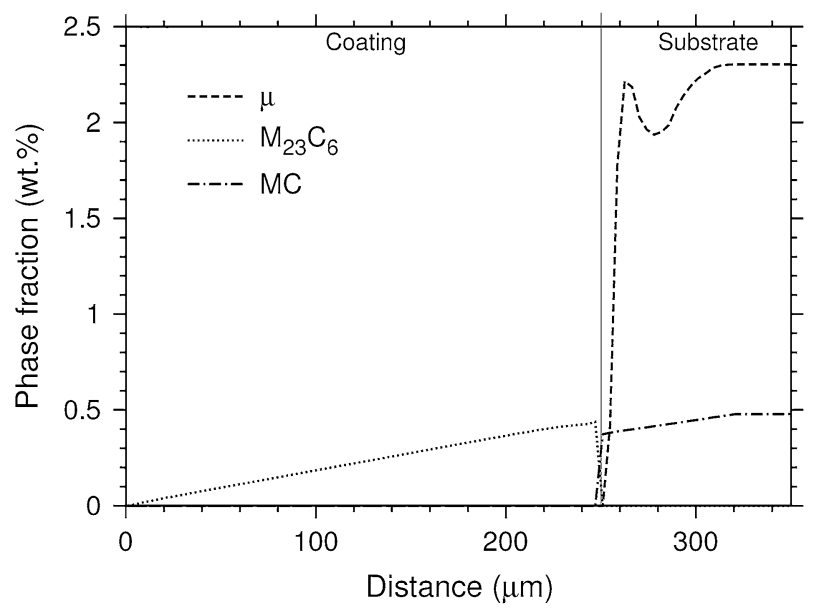

(b)

Fig. 5-Predicted phase profiles across the coating and interdiffusion zones of substrates in the AMDRY-997 coated MAR-M509 materials after aging at $1123 \mathrm{~K}\left(850^{\circ} \mathrm{C}\right)$ for $1000 \mathrm{~h}$ : (a) phases $\gamma, \gamma^{\prime}, \beta$, and $\sigma$, and (b) $\mu, \mathrm{M}_{23} \mathrm{C}_{6}$ and $\mathrm{MC}$ phases.

profiles at the interdiffusion zone can be observed clearly in the micrograph in Figure 10(a). As shown in Figures 10(a) and (b), close to this band, precipitates of $\mathrm{M}_{23} \mathrm{C}_{6}$ are found, and indeed the model predicts the presence of $\mathrm{M}_{23} \mathrm{C}_{6}$, mostly toward the substrate. The $\sigma$ phase is also observed on the substrate side of the interdiffusion zone. It is possible that in the latter stages of aging this transforms to the $P$ phase. ${ }^{[27]}$

\section{Observations after ageing at $1223 \mathrm{~K}\left(950^{\circ} \mathrm{C}\right)$} for 5000 hours

The calculated concentration profiles for the AMDRY-997/High-Cr superalloy sample, after being aged at $1223 \mathrm{~K}\left(950{ }^{\circ} \mathrm{C}\right)$ for 5000 hours, are shown in Figure 11. When compared with the AMDRY-997/ MAR-M509 system, it can be observed that the substrate contains lower concentrations of $\mathrm{Co}$ and $\mathrm{Cr}$, and therefore, these elements are expected to be removed from the coating much faster by interdiffusion with the substrate, following Fick's law. For the same reason, the

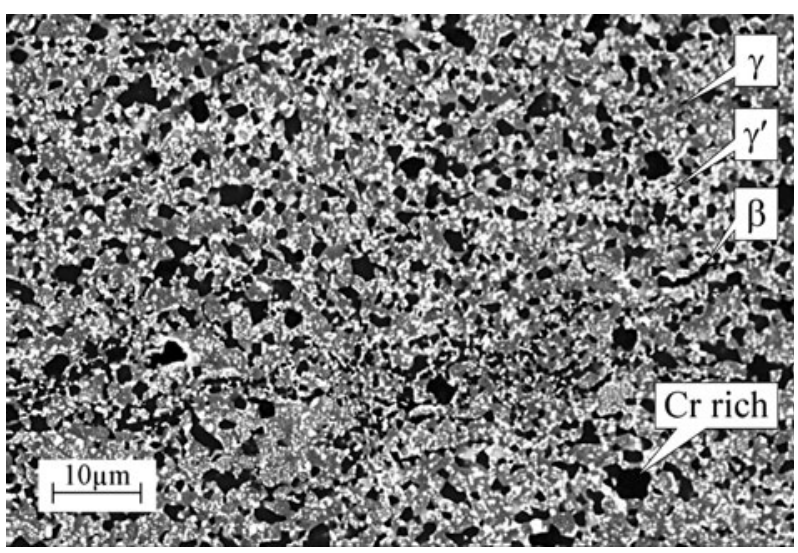

Fig. 6-Micrograph showing the phases observed in the bond-coat of MAR-M509 substrate sample after aging at $1123 \mathrm{~K}\left(850^{\circ} \mathrm{C}\right)$ for $1000 \mathrm{~h}$. The main phases $\gamma^{\prime}, \gamma$, and $\beta$ and a dark phase that contains a high $\mathrm{Cr}$ content can be identified (the shade varying from light to dark in the order mentioned).

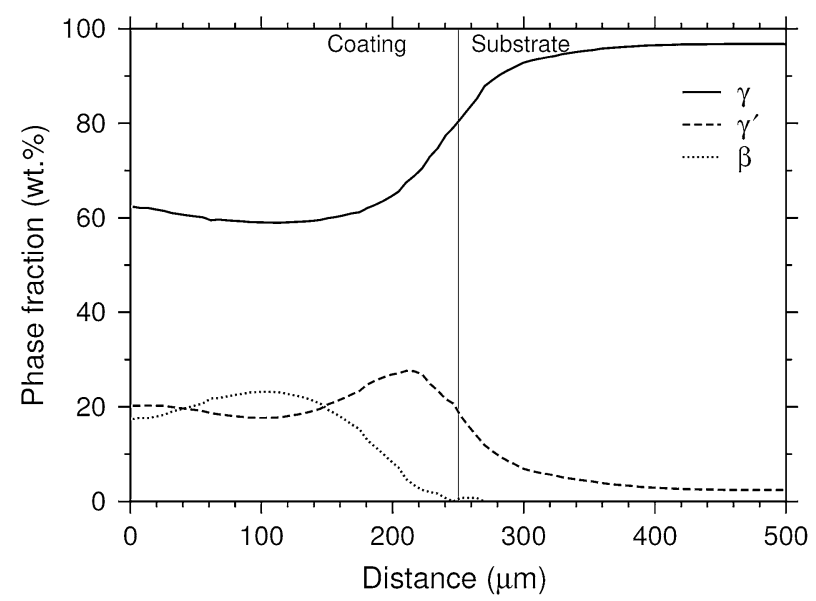

(a)

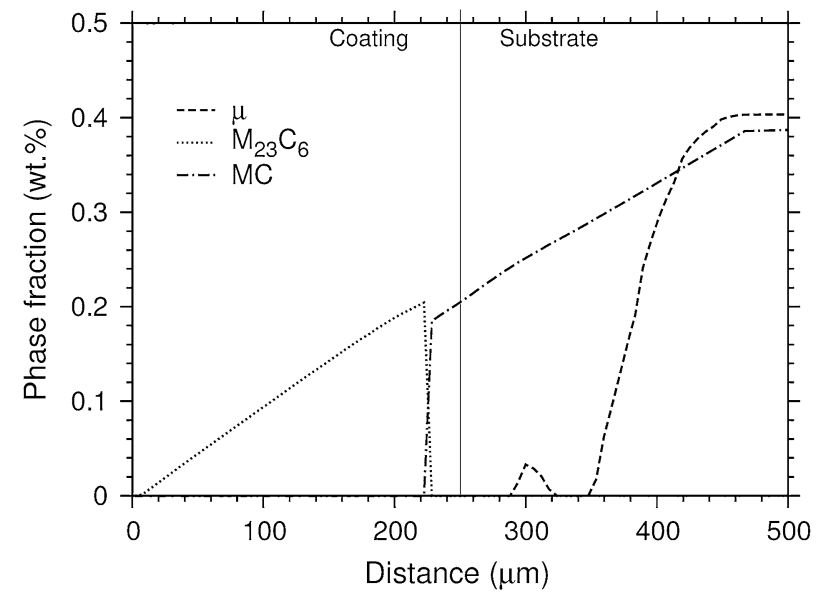

(b)

Fig. 7-Predicted phase profiles across the coating and interdiffusion zones of substrates in the AMDRY-997 coated MAR-M509 materials after aging at $1223 \mathrm{~K}\left(950{ }^{\circ} \mathrm{C}\right)$ for $1000 \mathrm{~h}$ : (a) phases $\gamma, \gamma^{\prime}, \beta, \sigma$, and $(b) \mu, \mathbf{M}_{23} \mathrm{C}_{6}$ and $\mathrm{MC}$ phases. 


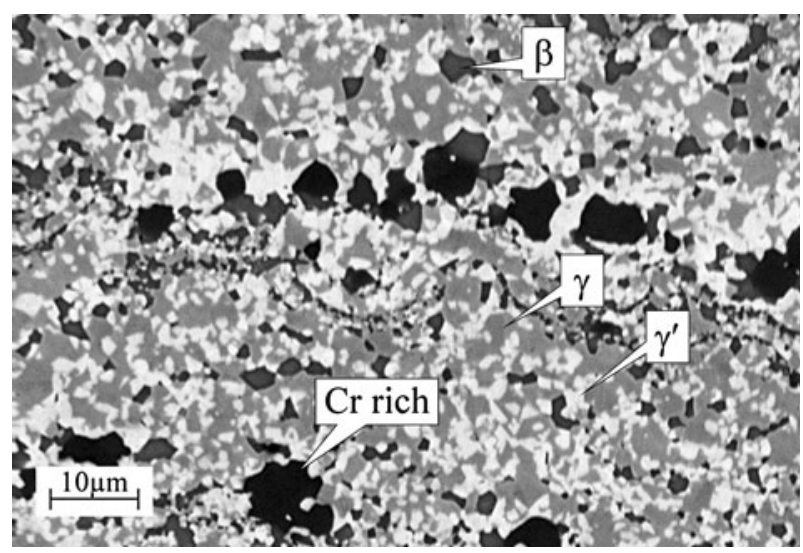

Fig. 8-Micrograph showing the phases observed in the bond-coat of MAR-M509 substrate sample after aging at $1223 \mathrm{~K}\left(950{ }^{\circ} \mathrm{C}\right)$ for $1000 \mathrm{~h}$. As in the sample at $1123 \mathrm{~K}\left(850^{\circ} \mathrm{C}\right)$ in Fig. 6 , the main phases $\gamma^{\prime}, \gamma, \beta$, and a dark phase that contains a high $\mathrm{Cr}$ content can be identified (the shade varying from light to dark in the order mentioned).

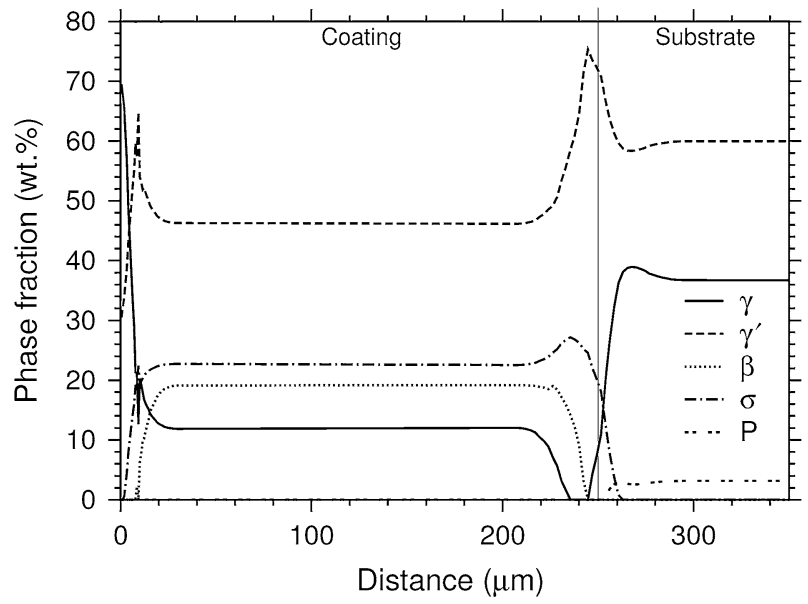

(a)

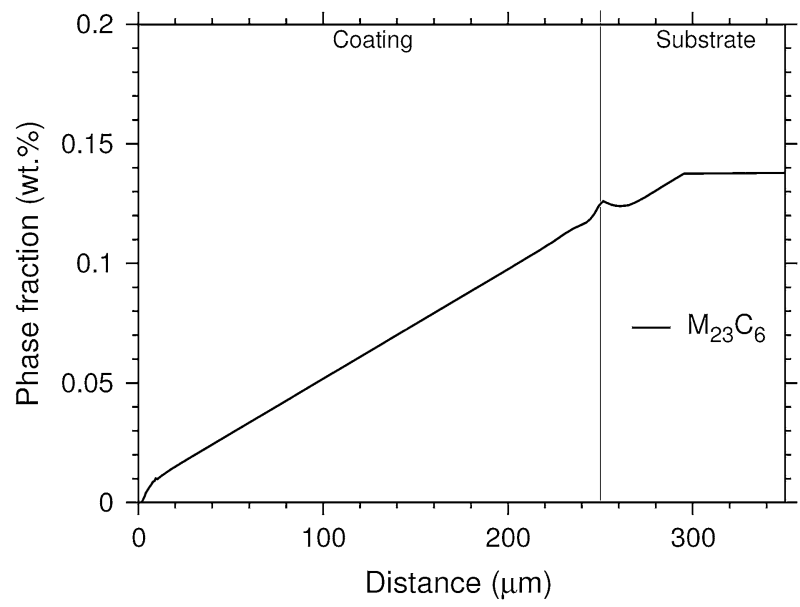

(b)

Fig. 9-Predicted phase profiles across the coating and interdiffusion zones of substrates in the AMDRY-997 coated High-Cr superalloy materials after aging at $1123 \mathrm{~K}\left(850^{\circ} \mathrm{C}\right)$ for $200 \mathrm{~h}$ : (a) phases $\gamma, \gamma^{\prime}, \beta, \sigma \& P$ and $(b) \mathrm{M}_{23} \mathrm{C}_{6}$ phase.
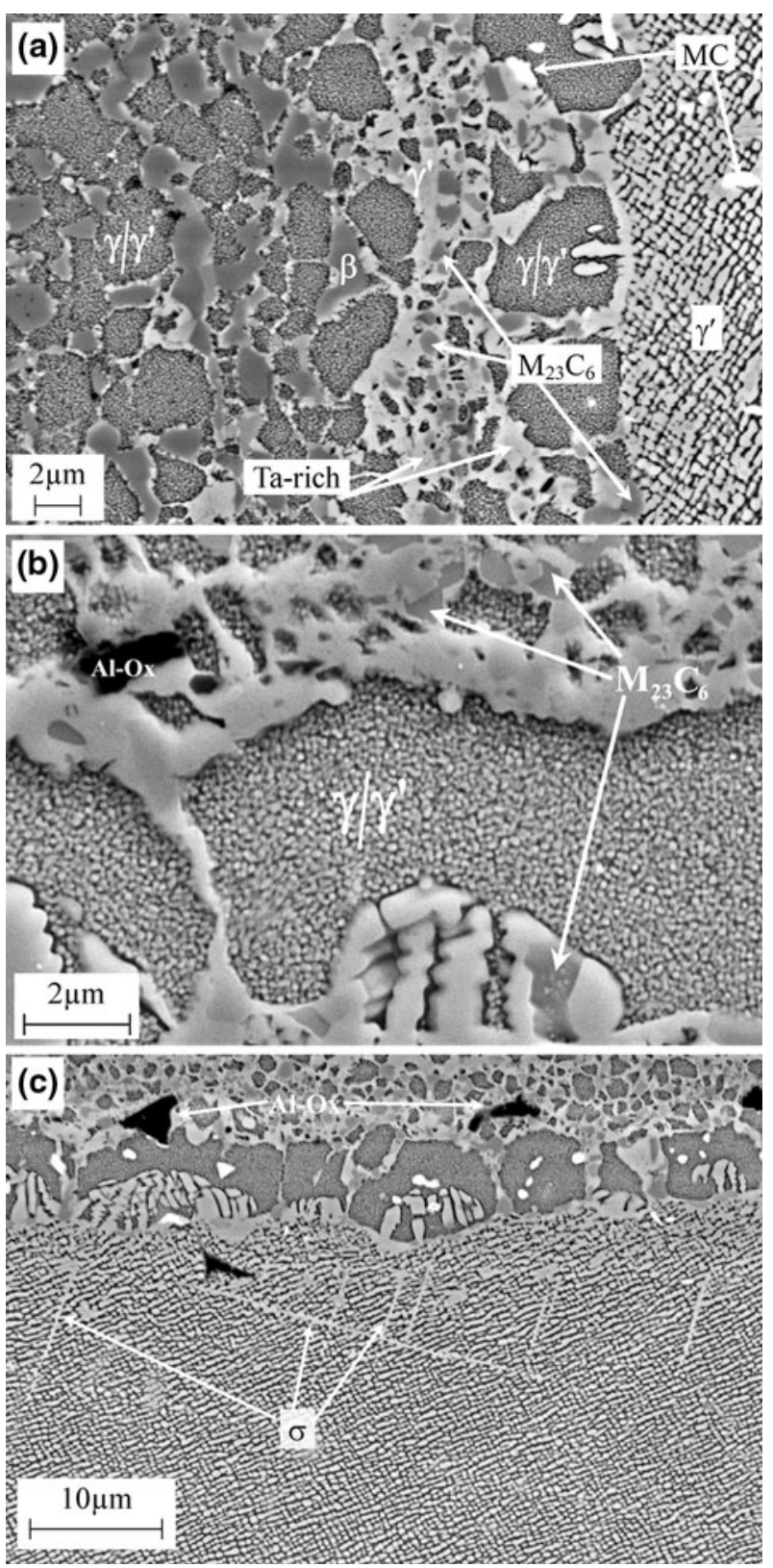

Fig. 10-Micrograph showing the phases observed in the bond-coat of High-Cr superalloy substrate sample after aging at $1123 \mathrm{~K}$ $\left(850{ }^{\circ} \mathrm{C}\right)$ for $200 \mathrm{~h}$

loss of $\mathrm{Al}$ from the coating through interdiffusion is anticipated to be slower. However, it is acknowledged that diffusion in a multicomponent system will not necessarily be driven by a concentration gradient as Fick's law predicts, and it is determined more accurately by the activity gradient of the diffusing species. The profiles also illustrate that at longer exposures, the elements such as $\mathrm{W}$ and Mo, which are present only in the substrate, can penetrate considerably into the coating.

The predicted phase profiles obtained at $1223 \mathrm{~K}$ $\left(950{ }^{\circ} \mathrm{C}\right)$ after 5000 hours are shown in Figure 12. The micrographs shown in Figure 13 identifies the phases 


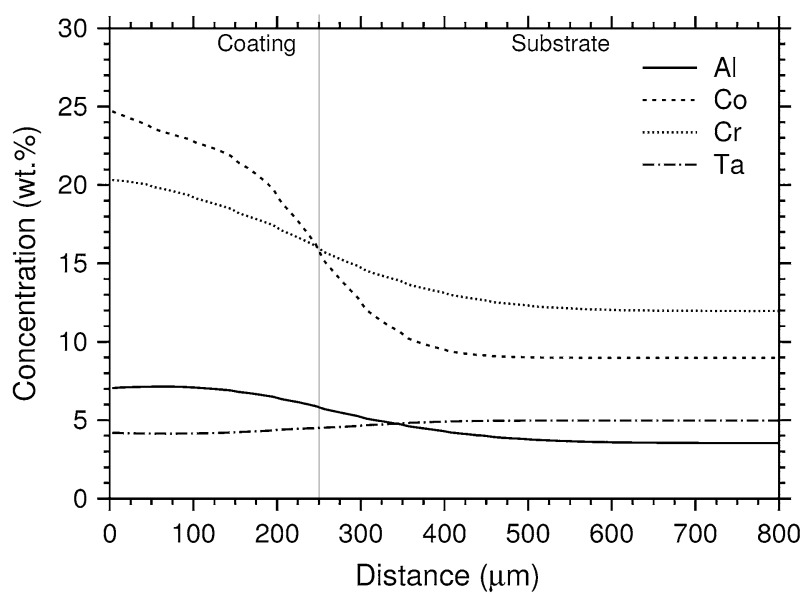

(a)

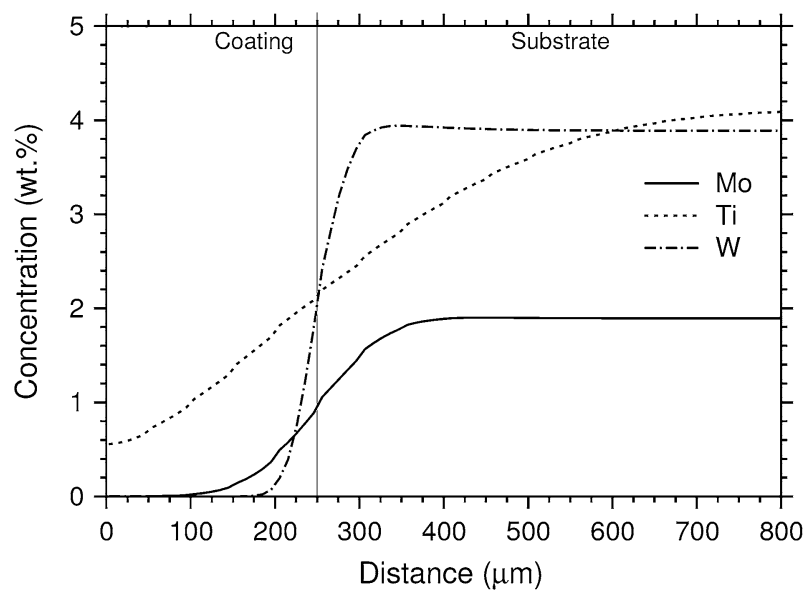

(b)

Fig. 11-Predicted concentration profiles across the coating and interdiffusion zones of the High-Cr superalloy substrate samples, after an aging at $1223 \mathrm{~K}\left(950^{\circ} \mathrm{C}\right)$ for $5000 \mathrm{~h}$.

observed in experimental samples that were subjected to an identical aging treatment. The graphs in Figure 12 reveal that the bulk of the coating is predicted to have a structure containing $\beta, \gamma^{\prime}$, and $\gamma$ phases in addition to some $\sigma$. The micrographs in Figures 13(a) and (b) corroborate this observation, except for the $\sigma$ phase, which is not observed in the coating of experimental specimens. The only carbide predicted is $\mathrm{M}_{23} \mathrm{C}_{6}$, whose concentration increases toward the substrate. The $P$ phase is also predicted near the interdiffusion zone. Figure 13(a) shows that near the oxidation surface, there is significant $\beta$ depletion, and the microstructure contains a high amount of $\gamma$ phase with a scatter of $\gamma^{\prime}$ particles. The simulation also predicts a high percentage of $\gamma\left(\sim 55 \mathrm{wt}\right.$ pct) compared with $\gamma^{\prime}(\sim 30 \mathrm{wt}$ pct $)$ but the precipitate-free layer and the $\beta$ depleted zone observed in the micrographs are not shown in the simulated results. It is possible to observe, however, that in the micrographs, the oxidation products contain $\mathrm{Cr}$, $\mathrm{Ta}$, and $\mathrm{Ti}$ in addition to $\mathrm{Al}$, although currently the model supports only the oxidation of Al. It is, therefore, possible that the discrepancies revealed in the phase

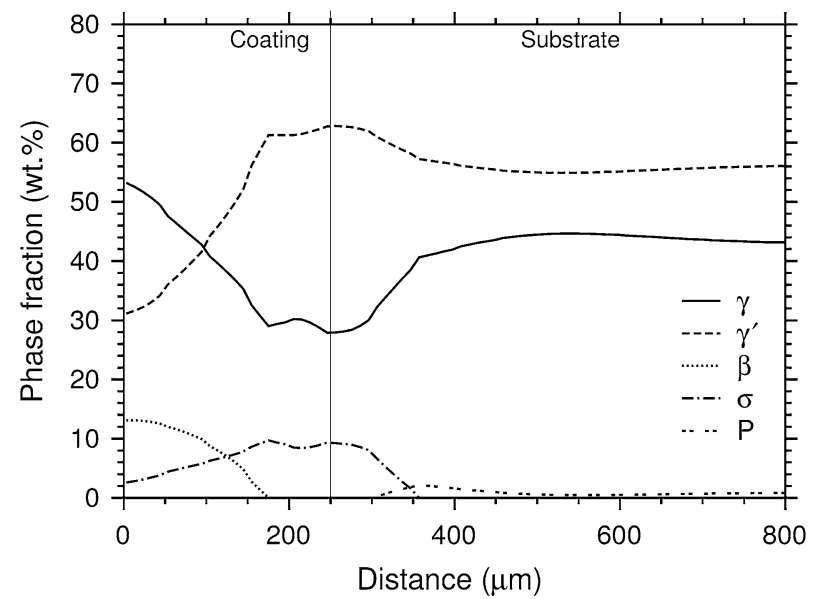

(a)

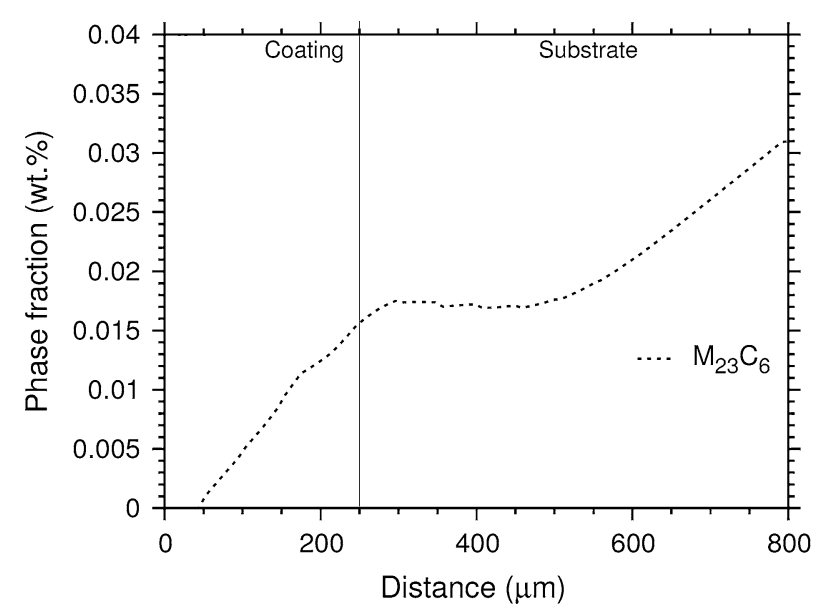

(b)

Fig. 12-Predicted phase profiles across the coating and interdiffusion zones of substrates in the AMDRY-997 coated High-Cr superalloy materials after aging at $1223 \mathrm{~K}\left(950{ }^{\circ} \mathrm{C}\right)$ for $5000 \mathrm{~h}$ : $(a)$ phases $\gamma, \gamma^{\prime}, \beta, \sigma$, and $P$, and $(b) \mathrm{M}_{23} \mathrm{C}_{6}$ phase.

composition in the vicinity of oxidation interface is caused by not allowing the additional elements mentioned to be oxidized, and it illustrates the importance of understanding the oxidation behavior of these complex systems.

It is of interest to note that the $\gamma^{\prime}$ concentration increases from the surface toward the interdiffusion zone where it reaches a plateau at $\sim 60 \mathrm{wt}$ pct, forming a layer high in $\gamma^{\prime}$ that is devoid of the $\beta$ phase. This layer carries the lowest amount of $\gamma(\sim 30 \mathrm{wt}$ pct $)$ in the system. Correspondingly, a layer enriched in $\gamma^{\prime}$, which also contains islands of $\gamma$, is observed in Figure 13(c), near where such a layer is predicted by the simulation. Associated with this layer, on the substrate side are $\mathrm{M}_{23} \mathrm{C}_{6}$ and a smaller number of $\mathrm{MC}$ carbide particles. Although the predicted $\mathrm{M}_{23} \mathrm{C}_{6}$ phase is in fact found in the system, the MC carbides are not forecast. The $P$ phase, although predicted, is not detected in the system. It could be possible that because of the close proximity of structures between carbides and TCP phases, the experimentally found phases are in a metastable state 

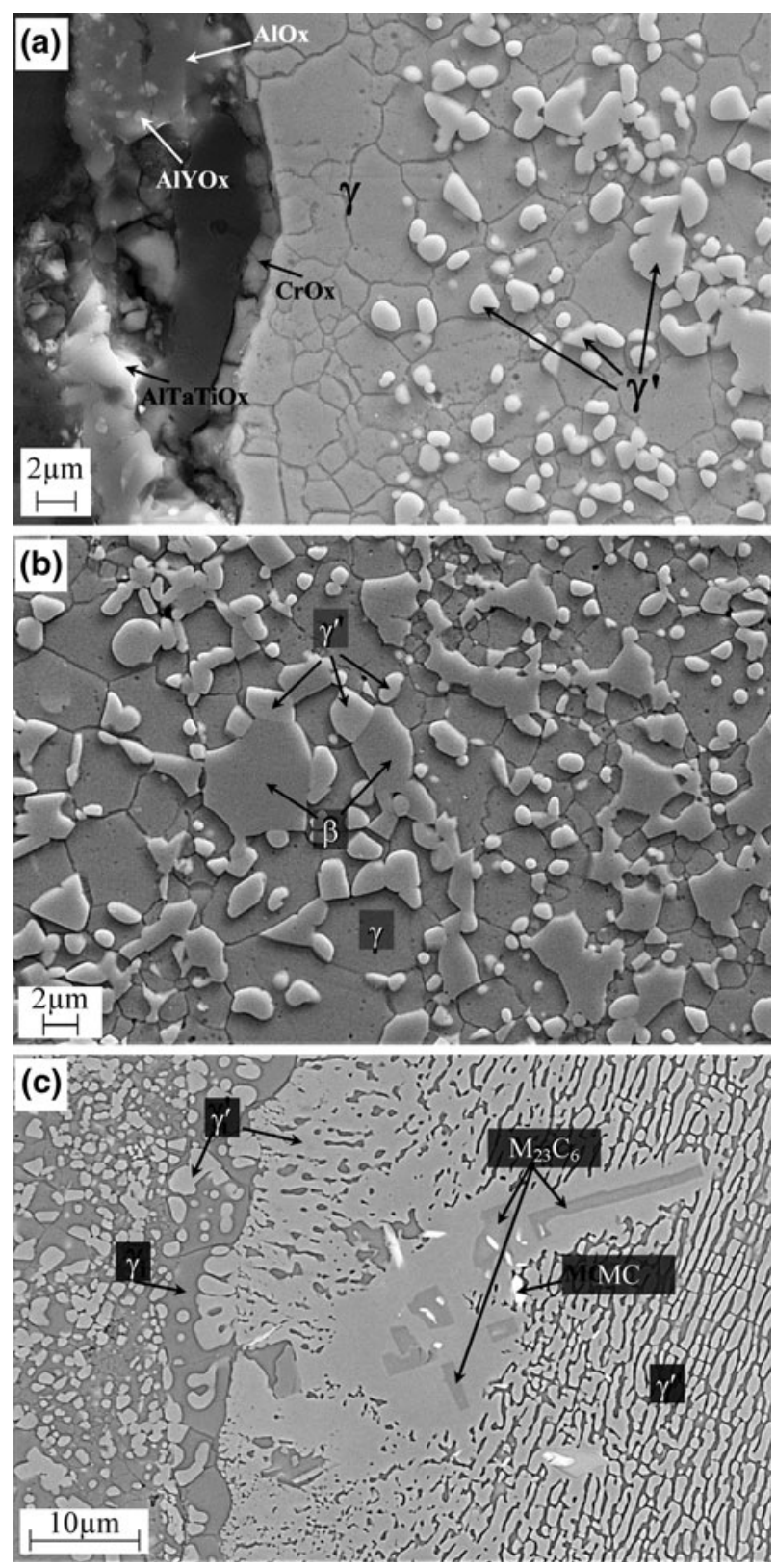

Fig. 13-Micrograph showing the phases observed in the bond-coat of High-Cr superalloy substrate sample after aging at $1223 \mathrm{~K}$ $\left(950^{\circ} \mathrm{C}\right)$ for $5000 \mathrm{~h}$.

and are not yet in the most stable form as predicted by thermodynamic modeling.

\section{AMDRY-997 Coating on CMSX-4 Substrate}

1. Observations after ageing at $1123 \mathrm{~K}\left(850^{\circ} \mathrm{C}\right)$ for 190 hours and 2000 hours

Figures 14 and 15 show the phase predictions for the AMDRY-997/CMSX-4 system heat treated at $1123 \mathrm{~K}$ $\left(850{ }^{\circ} \mathrm{C}\right)$ for 190 hours and 2000 hours, respectively. These profiles should be compared against the micrographs shown in Figure 16. The phase profiles are characterized by the phases $\gamma^{\prime}, \gamma, \beta$, and $\sigma$ in the coating as expected and $\gamma, \gamma^{\prime}$, and $\mu$ phase in the substrate after both 190 and 2000 hours. The carbide phase $\mathrm{M}_{23} \mathrm{C}_{6}$ is predicted for both coating and substrate. A discernible feature in both sets of profiles is the sharp peak of $\gamma^{\prime}$, which is located at the $\beta$-depletion layer closer to the oxidation interface. The two narrow bands of $\gamma^{\prime}$ identified in micrographs in Figures 16(a) and (c) are evidence of this feature in the experimental samples. The precipitate-free $\gamma$ layer adjacent to the $\gamma^{\prime}$ band is also recognizable in both experimental samples and in the simulated profiles. The $\beta$-free zone (marked in Figure 16(c)) and the associated band of $\gamma^{\prime}$ are in fact shown in many other samples and corresponding simulation results. It is possible to assume that as $\mathrm{Al}$ is removed during oxidation, the $\beta$ phase transforms to $\gamma^{\prime}$ and then to $\gamma$. The layer of $\gamma^{\prime}$ forms as $\beta$ degenerates to $\gamma^{\prime}$ and possibly $\gamma$, which ultimately transforms to the precipitate-free $\gamma$ layer, as more $\mathrm{Al}$ is removed by oxidation.

A thicker layer consisting of a high-proportion of $\gamma^{\prime}$, which can always be observed near the coating/ substrate boundary in experimental samples of AMDRY-997/CMSX-4, is another feature predicted consistently by the simulations as shown in the examples in Figures 14 and 15. A close-up of this layer is presented in the micrograph in Figure 16(b). The formation of such a layer can be attributed to the gradual transformation of the $\beta+\gamma^{\prime}+\gamma$-based coating to the $\gamma+\gamma^{\prime}$ based substrate because of the interdiffusion between the substrate and coating, mainly as a result of $\mathrm{Al}$ in the coating diffusing down its gradient to the substrate.

The simulation also reveals that the system as a whole is susceptible to the formation of $\mathrm{M}_{23} \mathrm{C}_{6}$ carbides. These types of carbides have been identified in experimental samples, although mainly in the interdiffusion zone within the layer of high $\gamma^{\prime}$ concentration as noted in Figure 16(b).

\section{Observations after aging at $1323 \mathrm{~K}\left(1050^{\circ} \mathrm{C}\right)$} for 190 hours

The concentration profiles shown in Figure 17 were obtained from a simulation performed at $1323 \mathrm{~K}$ $\left(1050{ }^{\circ} \mathrm{C}\right)$ for 190 hours for the AMDRY-997/CMSX4 system. In comparison with the AMDRY-997/High$\mathrm{Cr}$ superalloy system, the substrate has a lower $\mathrm{Cr}$ content and the coating is thicker. There are additional compositional differences with regard to the two Ni-based substrates that affect the development of concentration profiles (Table I), amongst which are the significantly higher concentration of $\mathrm{Al}$, $\mathrm{Ta}$, and $\mathrm{W}$ in CMSX-4 and the presence of the element Re.

Figure 18 reveals the predicted distribution of phases for the AMDRY-997/CMSX-4 sample in the $1323 \mathrm{~K}$ $\left(1050{ }^{\circ} \mathrm{C}\right) / 190$ hours annealing condition. In the coating, the microstructure consists of the $\gamma, \gamma^{\prime}$, and $\beta$ phases. Interestingly, the TCP and carbide phases are absent in the bulk of the coating at this temperature. At the coating/substrate interface, on the substrate side, a peak of $\sigma$ phase can be identified. A wider band of $P$ phase, which extends further into the substrate, is predicted also. A narrow layer of $\mathrm{M}_{23} \mathrm{C}_{6}$ carbide can 


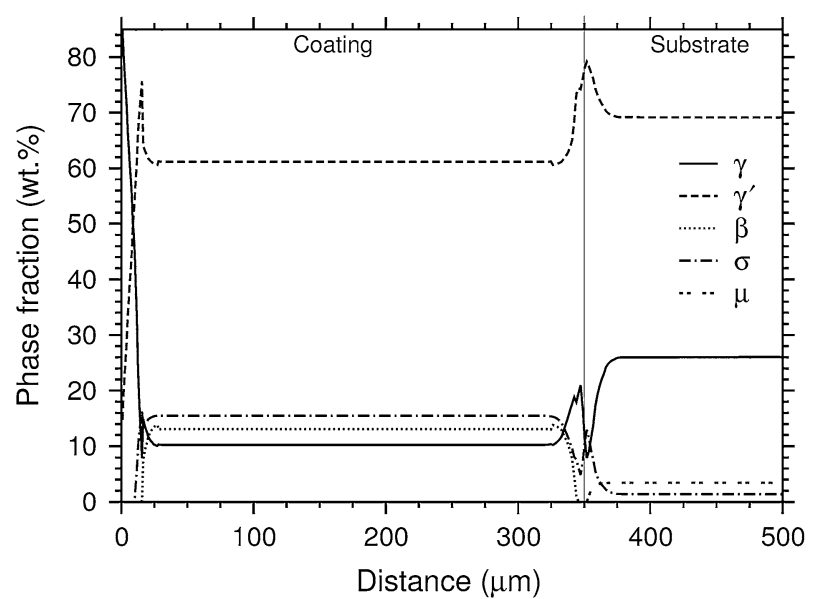

(a)

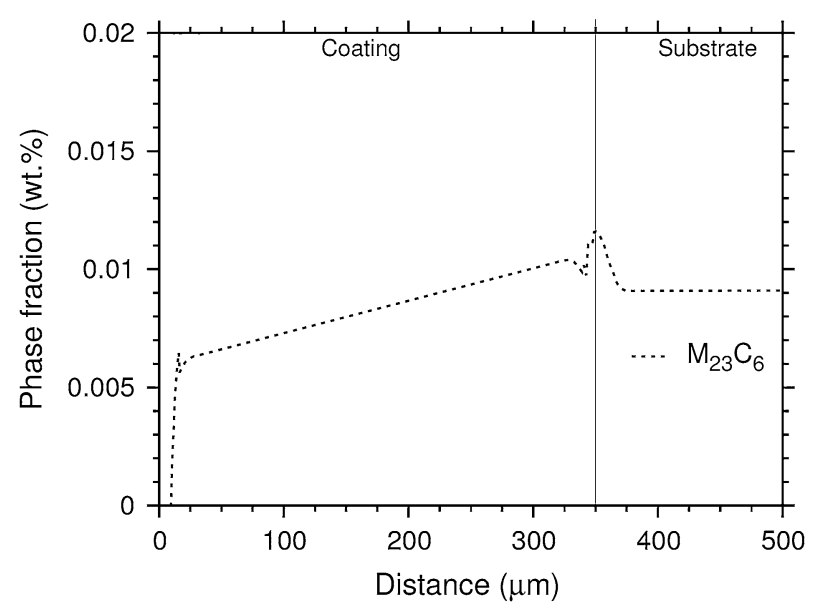

(b)

Fig. 14 - Predicted phase profiles across the coating and interdiffusion zones of substrates in the AMDRY-997 coated CMSX-4 materials after aging at $1123 \mathrm{~K}\left(850^{\circ} \mathrm{C}\right)$ for $190 \mathrm{~h}$ : $(a)$ phases $\gamma, \gamma^{\prime}, \beta, \sigma$, and $P$, and $(b) \mathrm{M}_{23} \mathrm{C}_{6}$ phase.

also be observed at the coating/substrate interface. The occurrence of $\beta$-depleted zones at either margins of the coating, the sharp peak of $\gamma^{\prime}$ near the oxidation interface at the perimeter of the $\beta$ depleted zone, and the high concentration of $\gamma^{\prime}$ and associated dip in $\gamma$ near the coating/substrate interface are the other important features observed in Figure 18.

Figure 19 shows the micrographs obtained from the AMDRY-997/CMSX-4 sample after aging at $1323 \mathrm{~K}$ $\left(1050{ }^{\circ} \mathrm{C}\right)$ for 190 hours. The $\beta$-depleted zone near the oxidation interface is clearly shown in Figure 19(a) along with a section of the coating where the presence of $\beta$ and $\gamma$ can be identified clearly. However, in these samples, as revealed by the micrographs, $\gamma^{\prime}$ phase could not be identified within the greater part of the coating, although its presence is predicted by the simulation in Figure 18. It seems that in this particular instance, the simulation underpredicts the amount of $\beta$ present at OAZ.

The mainly $\gamma^{\prime}$ band found at the coating/substrate boundary in Figure 19(b) coincides well with the high

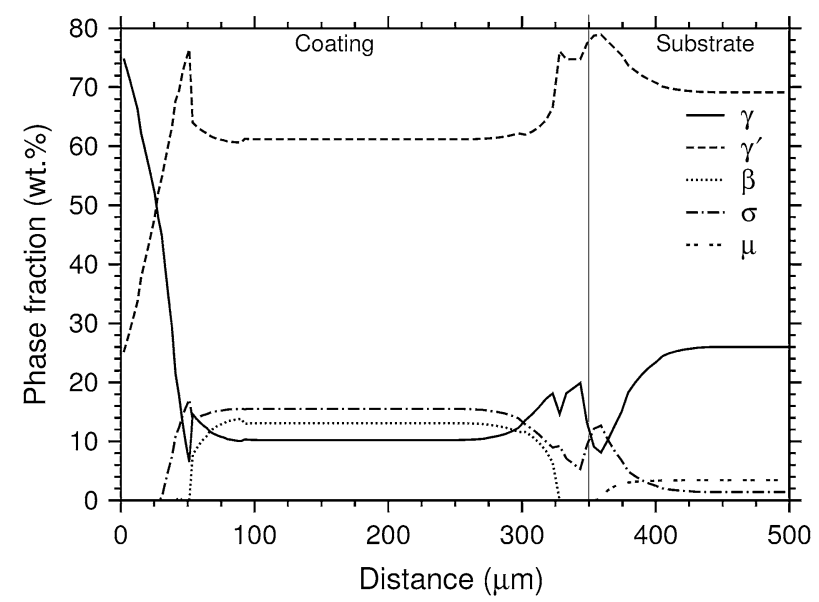

(a)

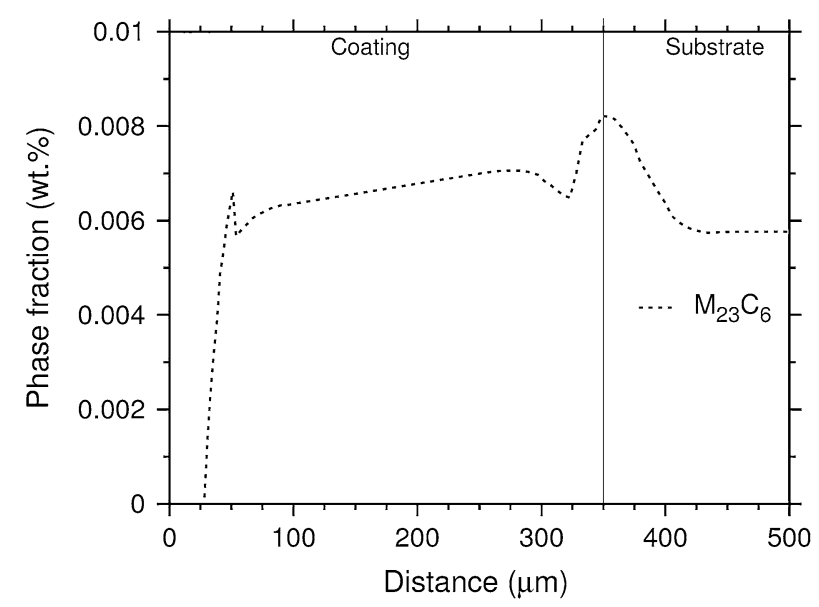

(b)

Fig. 15-Predicted phase profiles across the coating and interdiffusion zones of substrates in the AMDRY-997 coated CMSX-4 materials after aging at $1123 \mathrm{~K}\left(850^{\circ} \mathrm{C}\right)$ for $2000 \mathrm{~h}$ : $(a)$ phases $\gamma, \gamma^{\prime}, \beta, \sigma$, and $P$, and $(b) \mathrm{M}_{23} \mathrm{C}_{6}$ phase.

$\sim 65$ wt. pct $\gamma^{\prime}$ peak observed in the profiles in Figure 18. The light phase that occurs within the $\gamma^{\prime}$ phase in Figure 19(b) has been identified as a TCP phase, and it corresponds favorably with the $\sigma$ and $P$ phases predicted for this region. The other blocky particles identified in Figure 19(b) as MC carbides arise at approximately the same location as the $\mathrm{M}_{23} \mathrm{C}_{6}$ carbide layer is predicted by the simulation.

\section{Comparison of the Coating Performance on Three Different Substrates}

\section{Aging at $1123 \mathrm{~K}\left(850^{\circ} \mathrm{C}\right)$ for 1000 hours}

For the three coating/substrate systems, Figure 20 compares the predicted phase profiles generated after annealing at $1123 \mathrm{~K}\left(850^{\circ} \mathrm{C}\right)$ for 1000 hours. In the case of MAR-M509 and High-Cr superalloy substrates, the AMDRY-997 coating thickness was $250 \mu \mathrm{m}$, whereas for the CMSX-4 coating, it was $350 \mu \mathrm{m}$. As a result, the coating composition for the CMSX-4 substrate is the least affected because of interdiffusion with the 

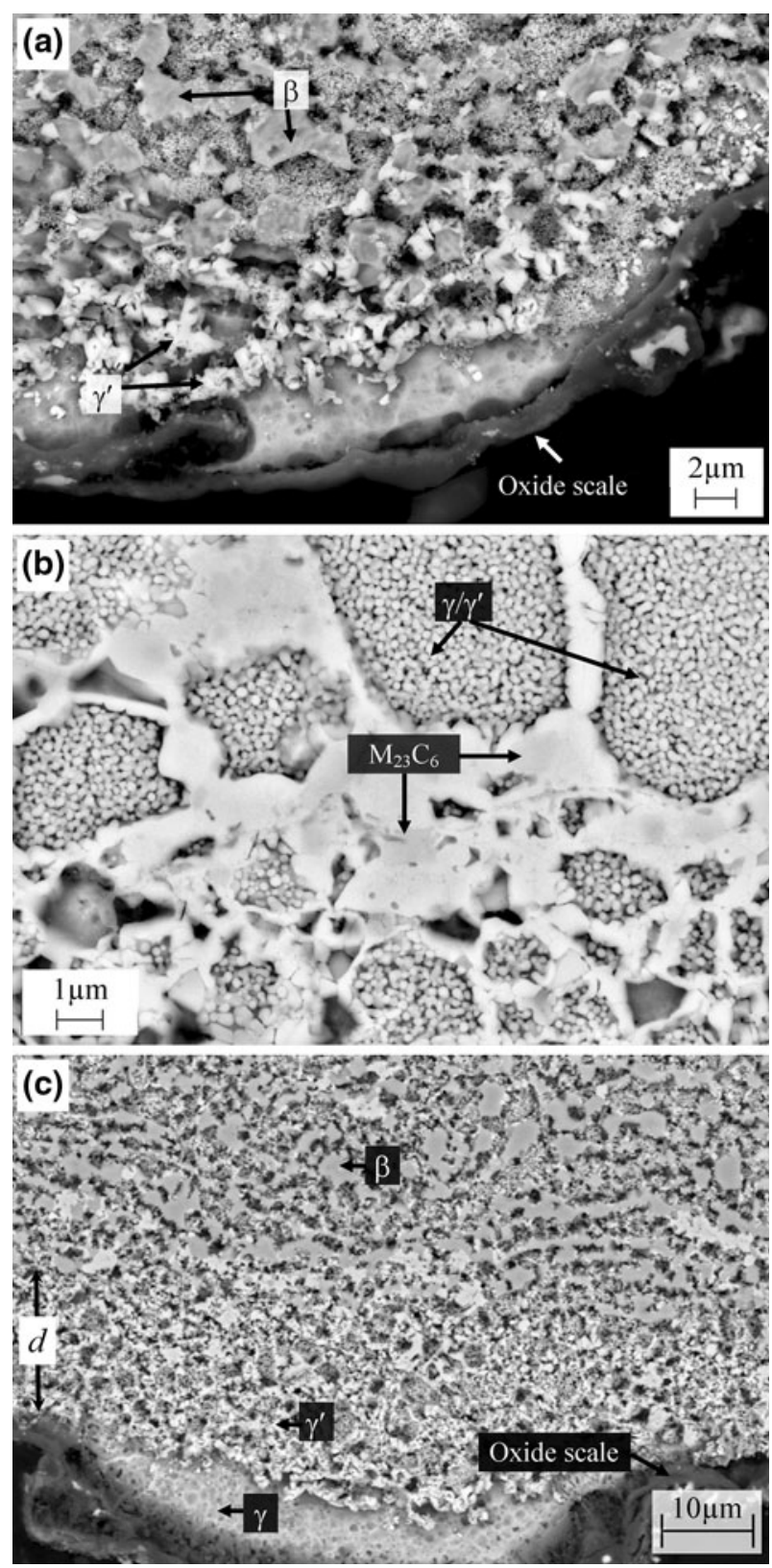

Fig. 16-Micrograph showing the phases observed in the bond-coat of CMSX-4 substrate sample after aging at $1123 \mathrm{~K}\left(850^{\circ} \mathrm{C}\right)$ for $(a)$ and (b) $190 \mathrm{~h}$ and (c) $2000 \mathrm{~h}$. The $\beta$ depletion layer is marked as $d$.

substrate. The coatings in all three systems have a phase structure based on $\gamma^{\prime}, \gamma, \beta$, and $\sigma$ phases, whose relative fractions vary among the systems. The phase structure of the substrates varies more considerably, from being a high $\gamma$-Co structure in MAR-M509 substrate to a more $\gamma^{\prime}$ based $\gamma / \gamma^{\prime}$ Ni-base structure in CMSX-4 substrate, with the High-Cr superalloy showing an intermediate $\gamma / \gamma^{\prime}$ proportion.

All systems show the presence of a $\gamma^{\prime}$ peak near the oxidation interface, with the AMDRY-997/CMSX-4 system showing a much larger peak concentration. The $\gamma^{\prime}$ concentration in the bulk coating is also larger in this system, possibly as a result of the thicker coating. The

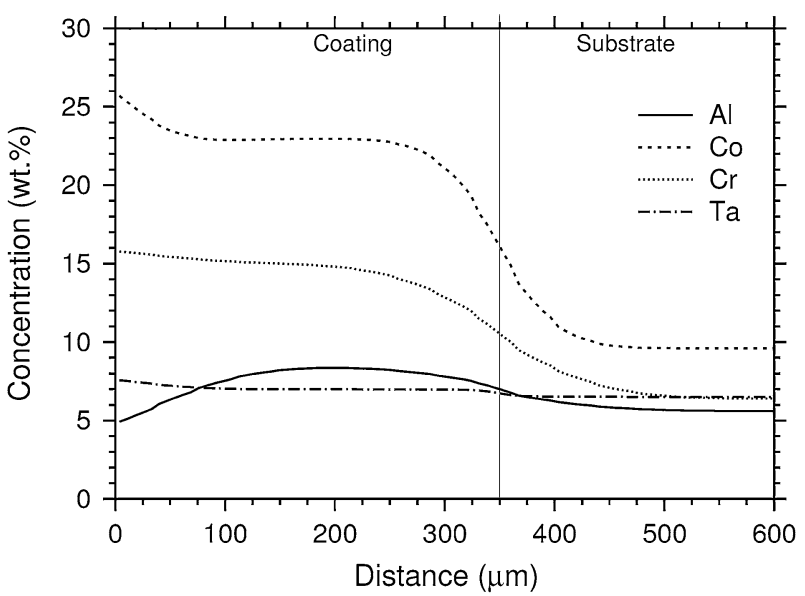

(a)

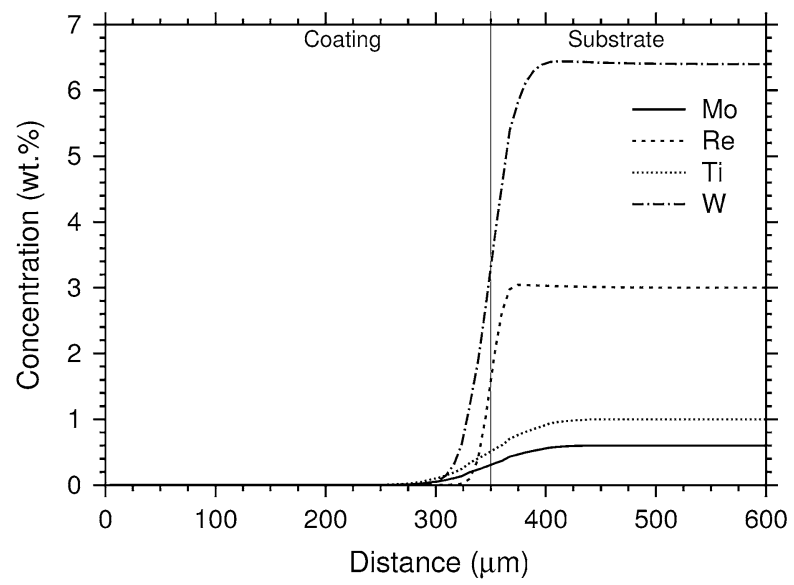

(b)

Fig. 17-Predicted concentration profiles across the coating and interdiffusion zones of the CMSX-4 substrate samples, after an aging at $1323 \mathrm{~K}\left(1050{ }^{\circ} \mathrm{C}\right)$ for $190 \mathrm{~h}$.

larger peak of $\gamma^{\prime}$ in the AMDRY-997/CMSX-4 at lower temperatures, is supported experimentally by the fact that a band of $\gamma^{\prime}$ is observed more prominently in that system; see for instance, Figures 16(a) and (c).

The graphs in Figure 20 reveal the presence of much broader $\gamma^{\prime}$ peaks at the coating/substrate interface, near the interdiffusion zone in AMDRY-997/High-Cr superalloy and AMDRY-997/CMSX-4 samples (although there is a detectable peak in AMDRY-997/MAR-M509 system, it is less intense). This prediction is supported by experimental observations as only the High-Cr superalloy and CMSX-4 based systems show a $\gamma^{\prime}$ enriched layer at the interface. In general, the layer observed in the AMDRY-997/CMSX-4 system is more continuous as revealed in Figure 21(a). It is more "blocky" in nature in the AMDRY-997/High-Cr superalloy samples as shown in Figure 21(b) for example, with the layer being more interrupted by $\gamma$ and other minor phases. This behavior perhaps can be explained with reference to the simulation predictions in Figure 20. In the $\gamma^{\prime}$ layer in the AMDRY-997/High-Cr superalloy system the fractional 


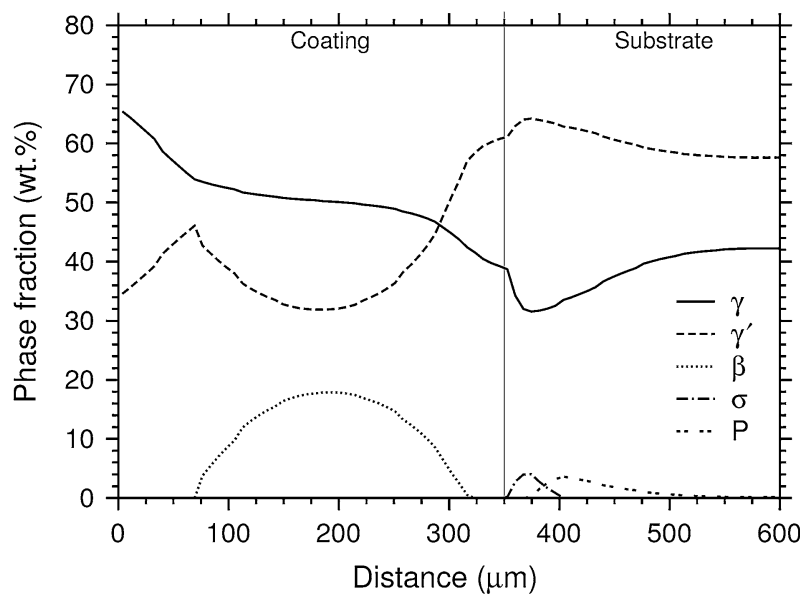

(a)

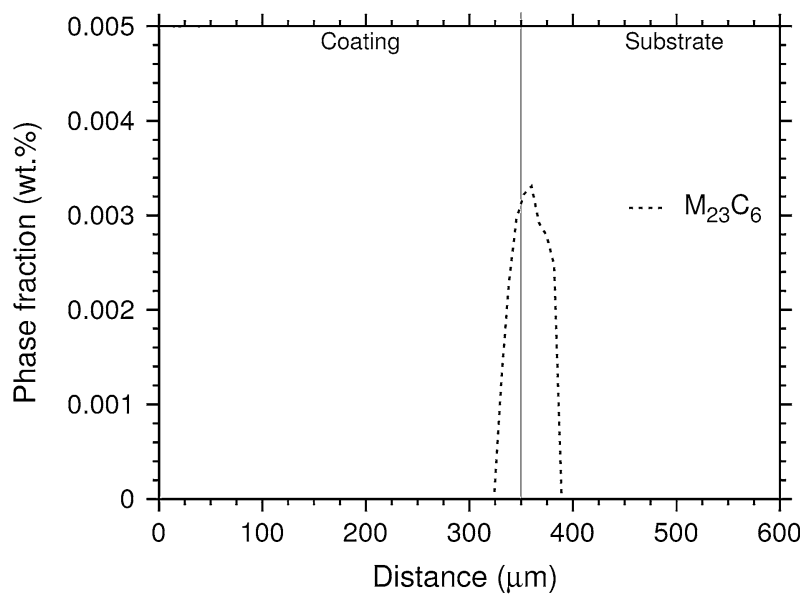

(b)

Fig. 18-Predicted phase profiles across the coating and interdiffusion zones of substrates in the AMDRY-997 coated CMSX-4 materials after aging at $1323 \mathrm{~K}\left(1050{ }^{\circ} \mathrm{C}\right)$ for $190 \mathrm{~h}$ : $(a)$ phases $\gamma, \gamma^{\prime}, \beta, \sigma$, and $P$ and $(b) \mathrm{M}_{23} \mathrm{C}_{6}$.

variation of other phases, particularly $\gamma$, is much wider compared with the AMDRY-997/CMSX-4 system, thereby giving a more complex phase mixture in the region.

It is also noticeable that all three systems show $\beta$ depleted zones near the oxidation interface and also at the coating/substrate boundary. At the oxidation interface, the depletion thickness is approximately the same for every system.

\section{Aging at $1223 \mathrm{~K}\left(950^{\circ} \mathrm{C}\right)$ for 1000 hours}

Figure 22 compares the phase profile predictions for three systems at $1223 \mathrm{~K}\left(950{ }^{\circ} \mathrm{C}\right)$ after aging for 1000 hours. Significant differences are observed between the phase structures and $\beta$ depletion rates in the three substrate materials. They appear more diffused compared with profiles calculated at $1123 \mathrm{~K}\left(850^{\circ} \mathrm{C}\right)$ for 1000 hours in Figure 20, as expected. The $\beta$-depletion zones are not predicted accurately except in the case of AMDRY-997/CMSX-4 because as outlined previously,
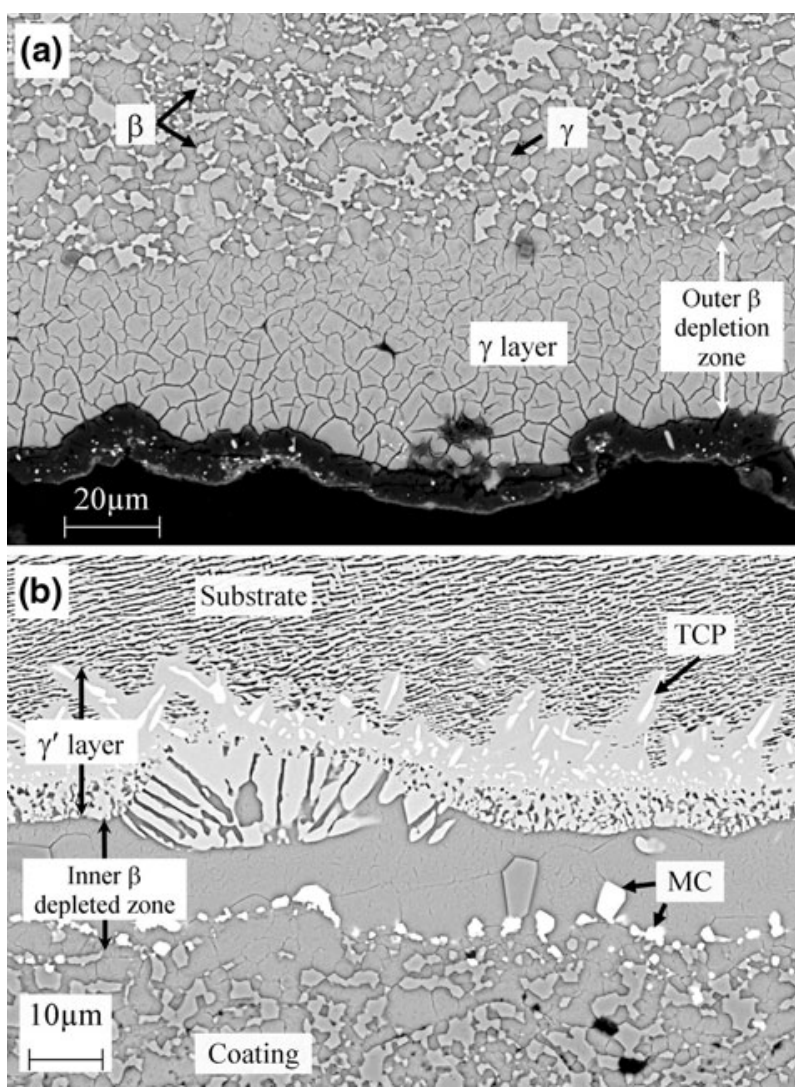

Fig. 19-Micrograph showing the phases observed in the bond-coat of CMSX-4 substrate sample after ageing at $1323 \mathrm{~K}\left(1050{ }^{\circ} \mathrm{C}\right)$ for $190 \mathrm{~h}$ : (a) oxidation affected zone, and (b) interdiffusion zone.

possibly because only $\mathrm{Al}$ is oxidized at the surface. The sharp $\gamma^{\prime}$ peak observed near the oxidation interface area is no longer detectable, although there is some evidence of a peak in the AMDRY-997/CMSX-4 sample. A $\gamma^{\prime}$ rich layer at the coating/substrate interface is identifiable in the High-Cr superalloy and CMSX-4 substrate samples and not in the MAR-M509 substrated sample as at $1123 \mathrm{~K}\left(850{ }^{\circ} \mathrm{C}\right)$. This layer is predicted to be much wider in the $1223 \mathrm{~K}\left(950^{\circ} \mathrm{C}\right) / 1000$ hours samples, a fact that is observed experimentally, for example by comparing the layer thicknesses in Figures 21 and 23 for the cases of High-Cr superalloy and CMSX-4 substrated samples.

\section{CONCLUSIONS}

A multicomponent diffusion model has been used to compare the microstructure evolution in three coated substrate systems, each having an MCrAlY coating similar in composition. Although there are discrepancies in some instances in terms of the exact type of phases, their quantities, and locations, it is believed that the model can be used as a useful predictive tool in its present state. Also, it has potential for subsequent improvements, some of which have been mentioned in 


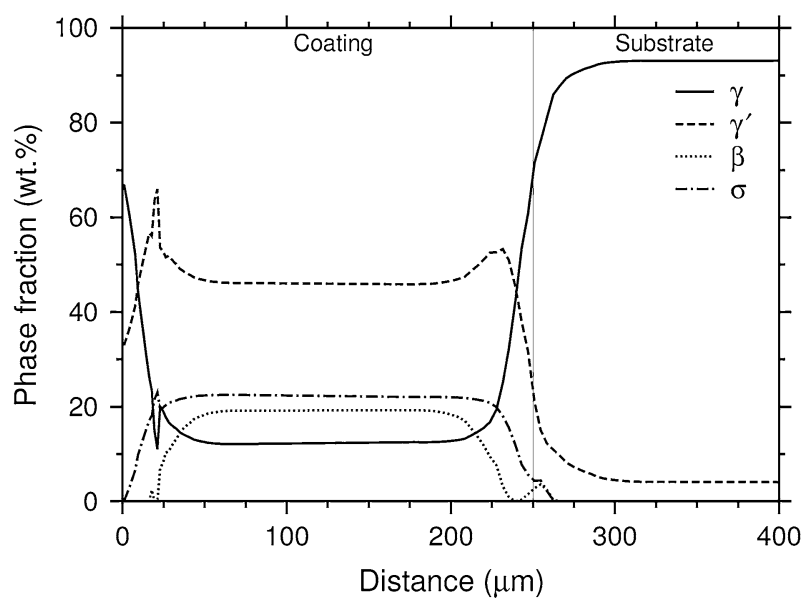

(a)

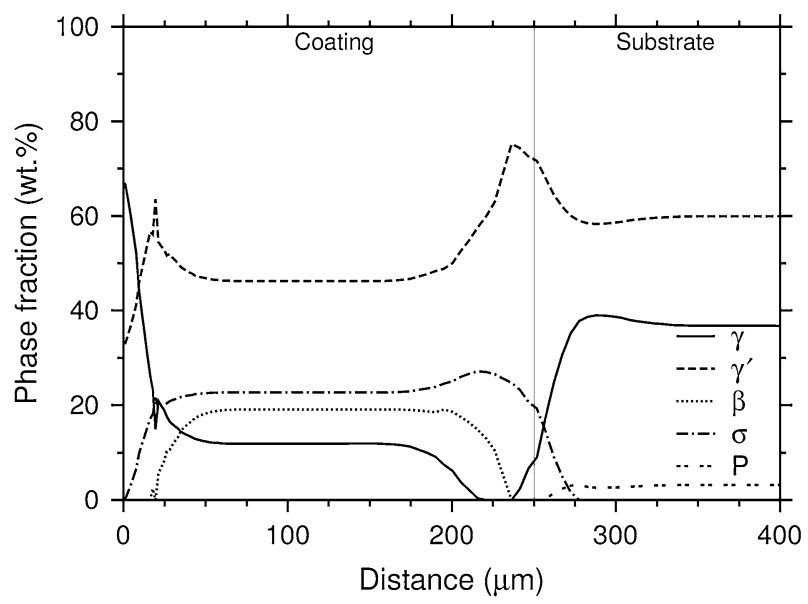

(b)

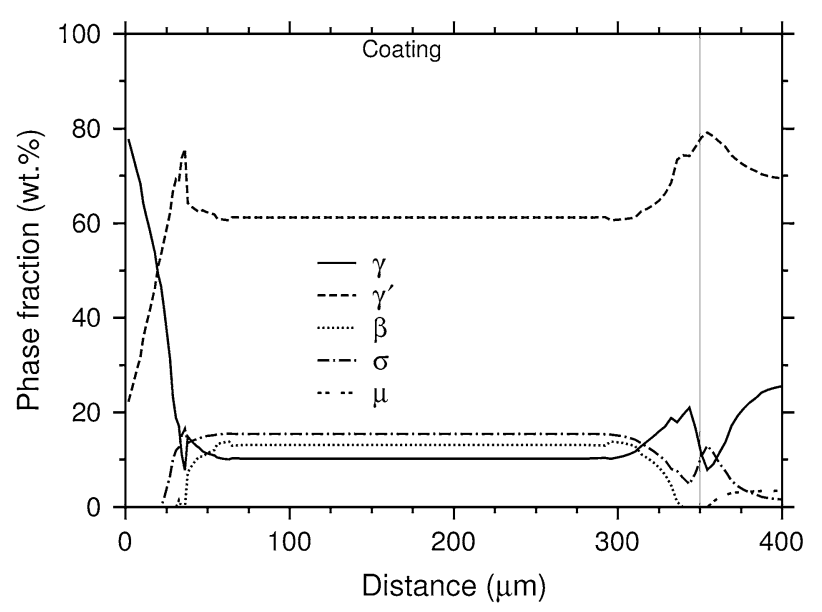

(c)

Fig. 20 - Comparison of predicted phase profiles across samples after ageing at $1123 \mathrm{~K}\left(850^{\circ} \mathrm{C}\right)$ for $1000 \mathrm{~h}$ in samples with substrates: (a) MAR-M509, (b) High-Cr superalloy, and (c) CMSX-4. Note that the initial coating thickness of CMSX-4 substrate sample is larger compared to the MAR-M509 and High-Cr superalloy substrate samples.

the text. The predictions made by the model were compared with experimental evidence at a range of temperatures and times. The observations agree well
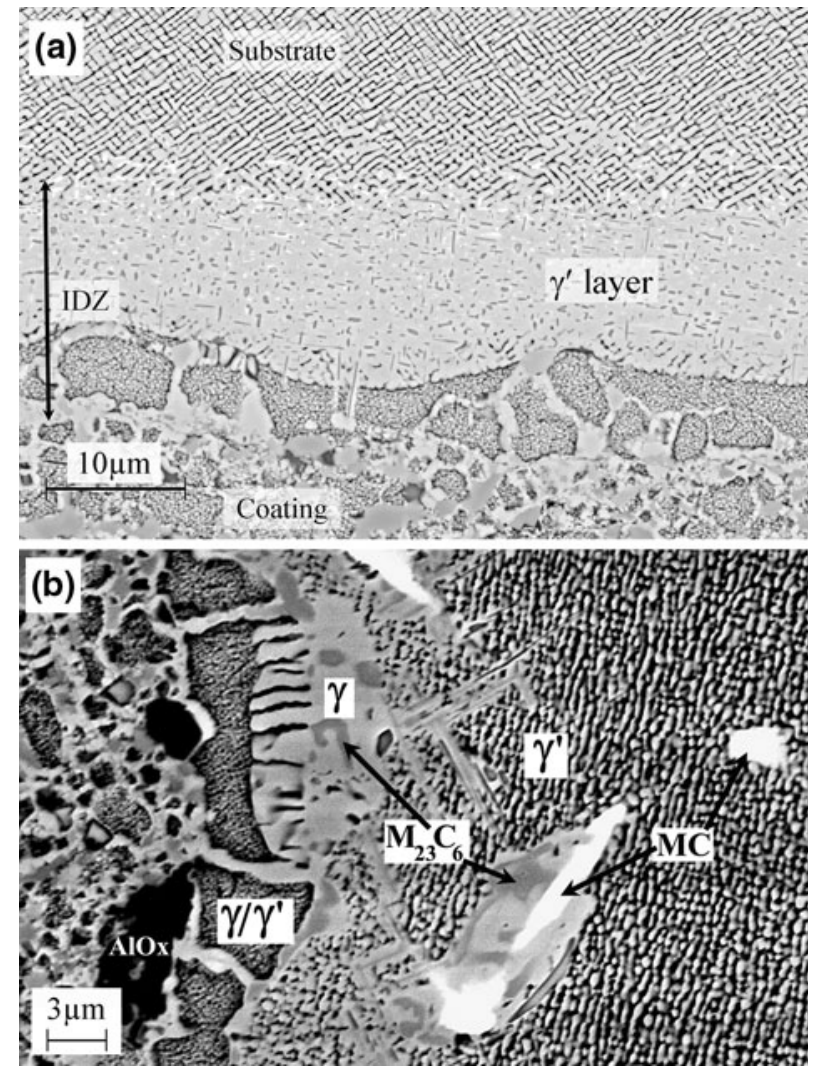

Fig. 21-Micrograph showing the $\gamma^{\prime}$ layer formed at the interdiffusion zone after aging at $1123 \mathrm{~K}\left(850^{\circ} \mathrm{C}\right)(a)$ after $2000 \mathrm{~h}$ in AMDRY-997/CMSX-4 samples and (b) after $1000 \mathrm{~h}$ in AMDRY997/High-Cr superalloy sample.

with the predictions in many areas including the precipitation of major phases such as $\gamma, \gamma^{\prime}$, and $\beta$ as a function of time and temperature. The presence of a $\gamma^{\prime}$-rich layer in the interdiffusion zone in CMSX-4 and High-Cr superalloy substrate samples, the depletion of the $\beta$ phase at the oxidation affected zone, and interdiffusion zone in all three systems are two important features that can be predicted by the model. Also, it can predict correctly the appearance of many types of minor phases (TCP and carbide phases) and their relative quantities - for example, the higher amount of TCP phases in the interdiffusion zone in High-Cr superalloy substrate samples compared with others. A key feature of this work has been the observation, both predicted and experimental, that clear differences exist between the phase evolution in a particular applied coating, which has implications for its performance and useful service life. It is therefore proposed that coatings must be considered to be part of a material system and that coating selection should take into account the nature of the substrate in order to optimize system performance. Furthermore, such considerations should lead to a capability to optimize coating systems for better performance and incorporate not only microstructure evolution characteristics but also factors such as mechanical properties of the coating system including the thermal 


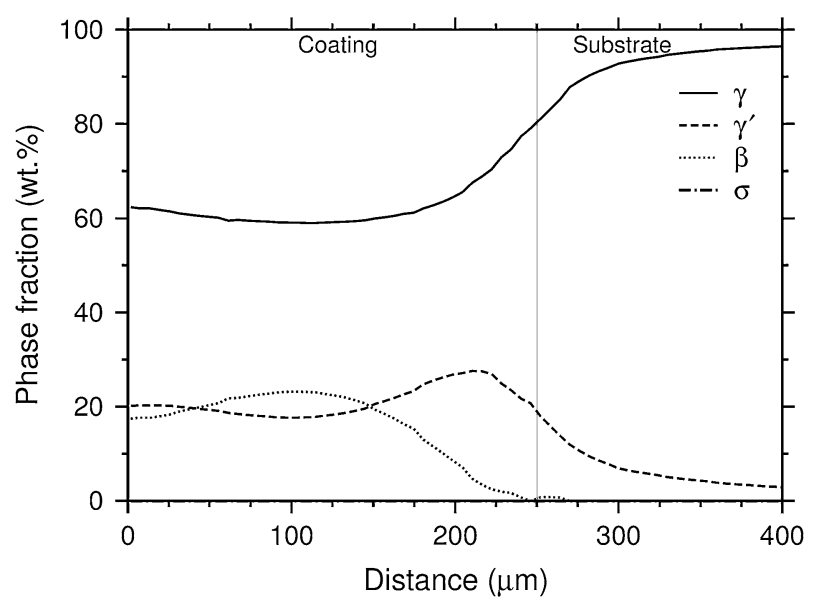

(a)

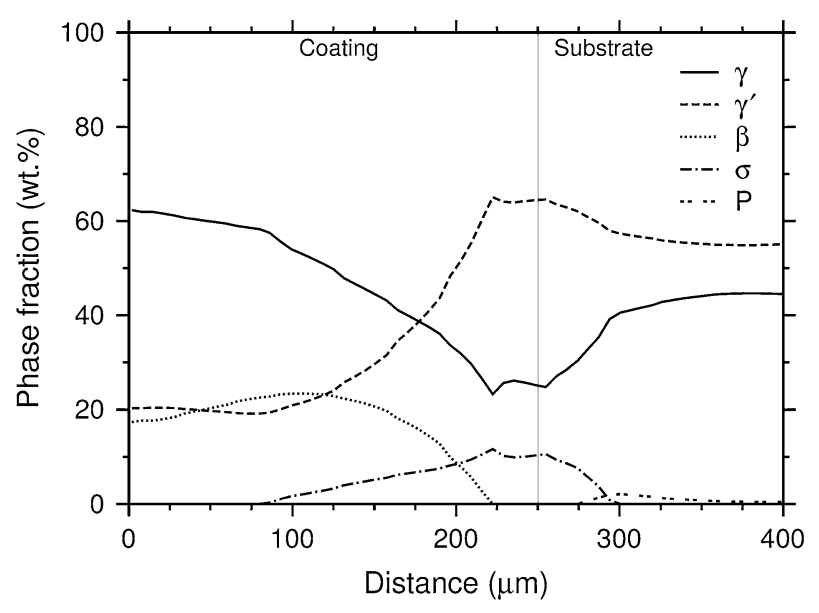

(b)

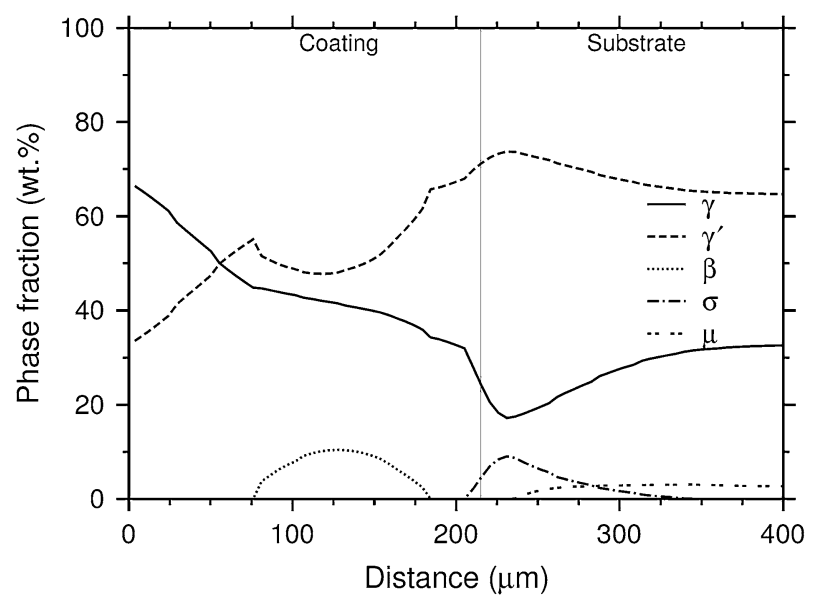

(c)

Fig. 22-Comparison of predicted phase profiles after ageing at $1223 \mathrm{~K}\left(950{ }^{\circ} \mathrm{C}\right)$ for $1000 \mathrm{~h}$ in samples with substrates: (a) MAR-M509, (b) High-Cr superalloy, and (c) CMSX-4.

barrier coating (TBC) layer and thermal expansion coefficient mismatches between the substrate and coating. ${ }^{[28,29]}$
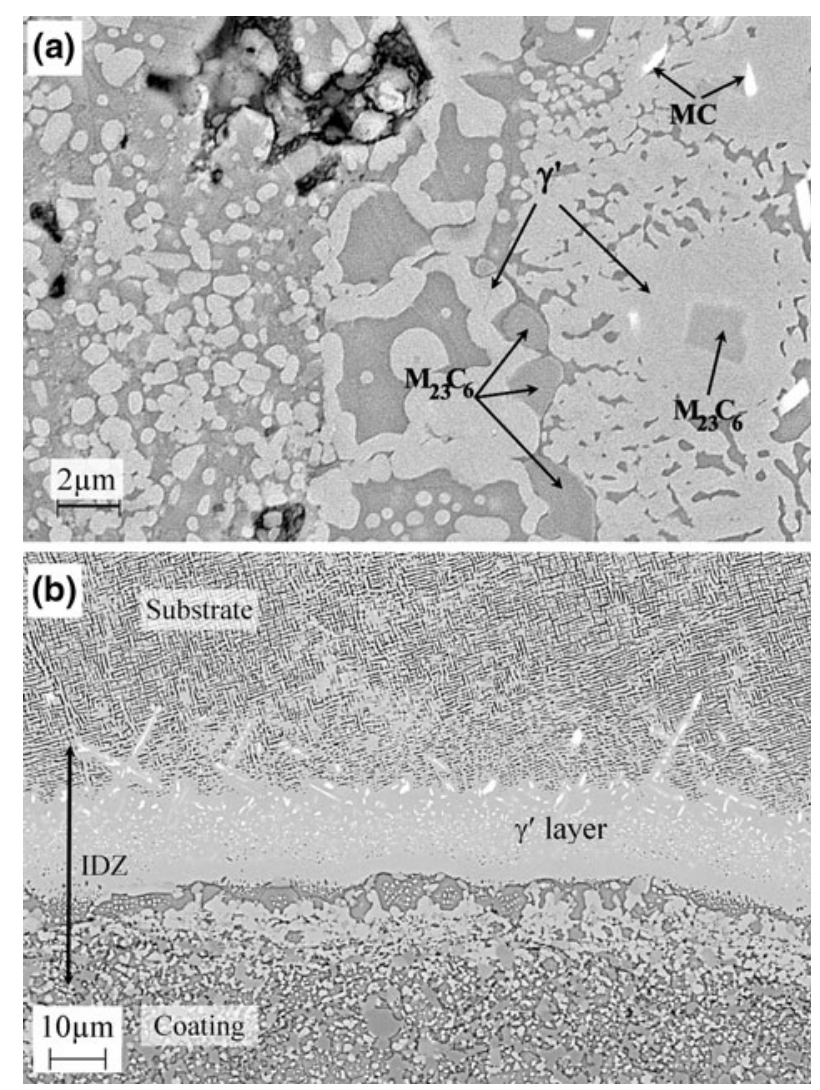

Fig. 23-Micrographs showing the interdiffusion zones after aging at $1223 \mathrm{~K}\left(950^{\circ} \mathrm{C}\right)$ (a) AMDRY-997/High-Cr superalloy for $1000 \mathrm{~h}$ and (b) AMDRY-997/CMSX-4 at $2000 \mathrm{~h}$.

\section{ACKNOWLEDGEMENTS}

The authors acknowledge the support of The Energy Programme, which is a Research Councils UK crosscouncil initiative led by EPSRC and contributed to by ESRC, NERC, BBSRC, and STFC, and specifically the Supergen initiative (Grants GR/S86334/01 and EP/ F029748). The authors thank following companies: Alstom Power Ltd., E.ON, National Physical Laboratory (NPL), QinetiQ, Rolls-Royce plc, RWE npower, Sermatech Ltd., Siemens Industrial Turbomachinery Ltd., and Tata Steel for their valuable contributions to the project. We appreciate the support given by the NPL staff, in particular Dr. Jim Robinson, on implementing MTDATA on a parallel computation environment and RWEnpower for supporting the doctoral studies of I. Di Martino and D. L. Oates.

\section{REFERENCES}

1. C.T. Sims, N.S. Stoloff, and W.C. Hagel, eds.: Superalloys II: HighTemperature Materials for Aerospace and Industrial Power, WileyInterscience Publication, John Wiley \& Sons, New York, 1987.

2. R.C. Reed, K.A. Green, P. Caron, T.P. Gabb, M.G. Fahrmann, E.S. Huron, and S.R. Woodard, eds.: Proc. 11th Int. Symp. on Superalloys, Seven Springs, PA, The Minerals, Metals \& Materials Society, Warrendale, PA, 2008.

3. M.S.A. Karunaratne, S.L. Ogden, S.D. Kenny, and R.C. Thomson: Mater. Sci. Technol., 2009, vol. 25 (2), pp. 287-99. 
4. A. Fick: Annal. Phys. Chem., vol. 94, 1855.

5. L. Onsager: Ann. N.Y. Acad. Sci., 1945, vol. 46 (241), pp. 241-65.

6. R.A. Swalin and A. Martin: Transactions of the American Institute of Mining and Metallurgical Engineers, The Institute, New York, 1956, pp. 567-72.

7. P.L. Gruzin, I.A. Polikarpov, and G.B. Fedorov: Fiz. Met. Metalloved., 1957, vol. 4 (1), pp. 94-102 (74-80).

8. T. Ustad and H. Sorum: Phys. Stat. Solidi A: Appl. Res., 1973, vol. 20, pp. 285-94.

9. A. Davin, V. Leroy, D. Coutsouradis, and L. Habraken: Cobalt, 1963, vol. 19, pp. 51-56.

10. N. Komai, M. Watanabe, Z. Horita, T. Sano, and M. Nemoto: Acta Metall., 1998, vol. 46 (12), pp. 4443-51.

11. M.S.A. Karunaratne, P. Carter, and R.C. Reed: Mater. Sci. Eng. A, 2000, vol. 281, pp. 229-33.

12. M.S.A. Karunaratne, P. Carter, and R.C. Reed: Acta Metall., 2001, vol. 49 (5), pp. 861-75.

13. M.S.A. Karunaratne and R.C. Reed: Acta Mater., 2003, vol. 51 (10), pp. 2905-19.

14. M.S.A. Karunaratne and R.C. Reed: Diffus. Defect Data, 2005, vols. 237-240, pp. 420-25.

15. T. Ikeda, A. Almazouzi, H. Numakura, M. Koiwa, W. Sprengel, and H. Nakajima: Diffus. Defect Data. Part A: Defect Diffus. Forum, 1997, vols. 143-147, pp. 275-78.

16. Y. Minamino, S.B. Jung, T. Yamane, and K. Hirao: Metall. Mater. Trans. A, 1992, vol. 23A, pp. 2783-90.

17. S. Frank, U. Sodervall, and C. Herzig: Diffus. Defect Data. Part A: Defect Diffus. Forum, 1997, vol. 143-147, pp. 245-50.

18. H. Wei, X. Sun, Q. Zheng, H. Guan, and Z. Hu: Acta Mater., 2004, vol. 52, pp. 2645-51.
19. R. Nakamura, K. Takasawa, Y. Yamazaki, and Y. Iijima: Intermetallics, 2002, vol. 10, pp. 195-204.

20. J. Crank and P. Nicolson: Proc. Cambridge Philosophical Society XLIII:, 1947, vol. 50 (-67), pp. 50-67.

21. S.M. Meier, D.M. Nissley, and K.D. Sheffler: Technical Report NASA Contractor Report 18911/NAS3-23944, National Aeronautics and Space Administration, NASA Lewis Research Center, 1991.

22. R.H. Davies, A.T. Dinsdale, and J.A. Gisby: MTDATA Handbook: Application Interface Programming Guide, National Physical Laboratory, Teddington, Middlesex, UK, 1998.

23. R.H. Davies, A.T. Dinsdale, J.A. Gisby, J.A.J. Robinson, and S.M. Martin: CALPHAD, 2002, vol. 26 (2), pp. 229-71.

24. N. Saunders: Proc. Eighth International Symposium on Superalloys (Superalloys 1996), R.D. Kissinger, M.V. Nathal, D.J. Deye, T.M. Pollock, D.L. Anton, D.A. Woodford, and A.D. Cetel, eds., Seven Springs, PA, The Minerals, Metals \& Materials Society, Warrendale, PA, 1996, pp. 101-10.

25. W.D. Murray and F. Landis: Trans. Am. Soc. Mech. Eng., 1959, vol. 81, pp. 106-12.

26. M.J. Starink and R.C. Thomson: J. Mater. Sci., 2001, vol. 36 (23), pp. 5603-08.

27. M.S.A. Karunaratne, C.F. Rae, and R.C. Reed: Metall. Mater. Trans. A, 2001, vol. 32A, pp. 2409-21.

28. U. Hermosilla, M.S.A. Karunaratne, I.A. Jones, T.H. Hyde, and R.C. Thomson: Mater. Sci. Eng. A, 2009, vols. 513-514, pp. 302-10.

29. U. Hermosilla, M.S.A. Karunaratne, I.A. Jones, T.H. Hyde, and R.C. Thomson: Proc. Institution of Mechanical Engineers Part L-Journal of Materials- Design and Applications., 2009, vol. 223 (L1), pp. 41-51. 